\title{
Estrategias metacognitivas en el aprendizaje del clarinete
}

Tesis de Maestría en Psicología de la Música Facultad de Bellas Artes Universidad Nacional de La Plata, Buenos Aires

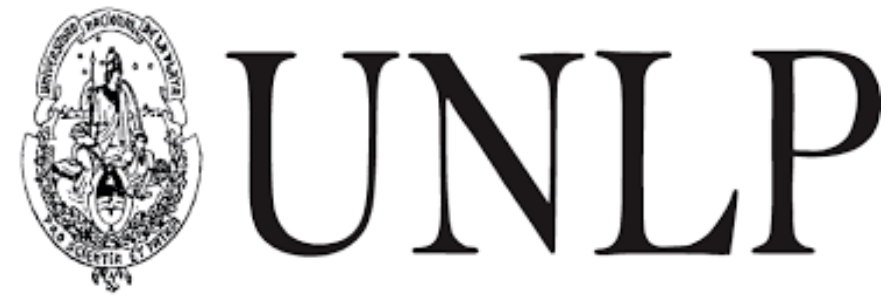

\section{Paula Beatriz Caputo}

Directora de Tesis: Dra. María del Carmen Malbrán

Co-Directora de Tesis: Dra. María Andrea Farina 
Dedico este trabajo a mi madre Delia, que me brindó su apoyo siempre.

A mi esposo Antonio, a quien debo el empuje constante para finalizarlo. A mis amigos que, de alguna forma u otra, siempre estuvieron presentes con buenos consejos. A todos ellos, gracias por su amor y confianza incondicional. 


\section{Agradecimientos}

Muchas personas han colaborado en la realización de este trabajo. De manera especial quisiera reconocer la ayuda brindada por la Dra. María del Carmen Malbrán, directora de esta tesis y a la Dra. María Andrea Farina, co-directora de tesis, quienes supieron guiarme con dedicación. Gracias a las autoridades y docentes de los Conservatorios Julián Aguirre, Astor Piazzolla y Juan Pedro Esnaola que me abrieron sus puertas para realizar el trabajo de campo de la presente investigación.

Gracias a los grandes maestros que compartieron conmigo el amor y la pasión por el conocimiento y la investigación, el arte y la música, en especial a la Dra. Silvia Malbrán y al Mtro. Néstor Tomassini. 


\title{
Resumen
}

Se presentan los resultados obtenidos al analizar las estrategias metacognitivas empleadas por clarinetistas en formación. La metacognición y la teoría triárquica de la inteligencia permitieron elaborar herramientas de análisis del proceso de aprendizaje instrumental, evidenciando el grado de autorregulación de los estudiantes de clarinete y la importancia del rol del docente de instrumento como transmisor de estrategias, como modelo y guía. Los clarinetistas en formación son capaces de reflexionar sobre el propio proceso de estudio, más allá del nivel de ejecución en que se encuentren. Los que poseen mayor experticia, están en mejores condiciones para verbalizar las estrategias utilizadas durante la práctica instrumental. Palabras claves: clarinete, estrategias, metacognición, teoría triárquica de la inteligencia, autorregulación.

\begin{abstract}
The results obtained by analyzing the metacognitive strategies employed by clarinetists in training are presented. Metacognition and the triarchic theory of intelligence allowed to develop tools for analyzing the instrumental learning process, for demonstrating the degree of self-regulation that clarinet students have, and to valuing the importance of the role of teachers of the instrument in the transmission of strategies, also as a model and guide to follow. In conclusion, clarinetists trainees are able to think about their own study process beyond the level of mastery they have. Those with greater expertise are more able to verbalize the strategies used during the instrumental practice.
\end{abstract}

Keywords: clarinet, strategies, metacognition, triarchic theory of intelligence, self-regulation. 
Índice

Capítulo 1. Introducción e información general ........................................................... 1

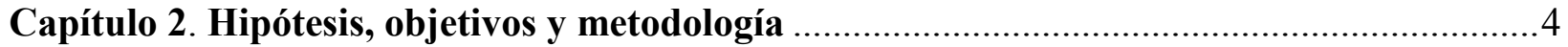

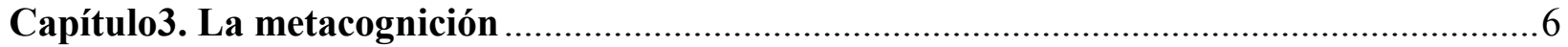

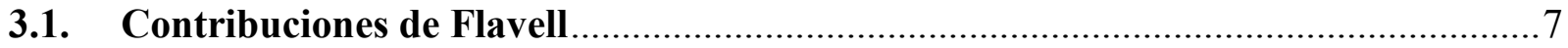

3.2. Teoría Triárquica de la Inteligencia (The triarchic mind) de Robert Sternberg .....9

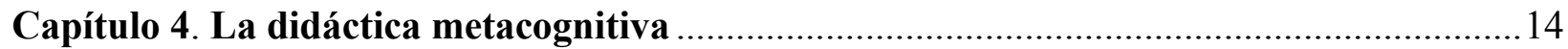

4.1. Estrategias metacognitivas del alumno. Aportes del docente. ............................... 14

4.2. El aprendizaje musical desde la mirada metacognitiva ................................. 17

Capítulo 5. Análisis de las estrategias metacognitivas de instrumentistas en formación .....21

5.1. El estudio eficaz del clarinete. Autorregulación................................................21

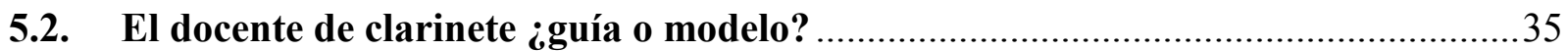

5.3. Observaciones y herramientas metacognitivas .......................................... 42

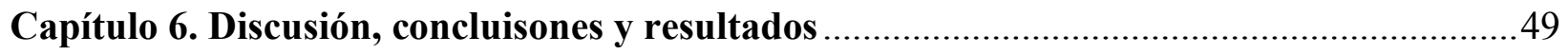

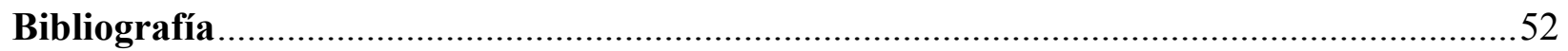

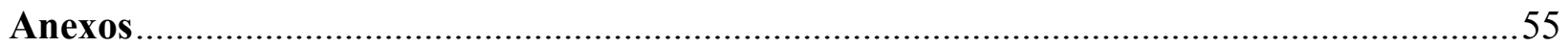




\section{Lista de figuras y tablas}

Figura 1. Síntesis de la Teoría Triárquica de la Inteligencia. Descripción de las subteorías....12

Figura 2. Rango de edades de los estudiantes encuestados ..............................23

Figura 3. Instituciones de formación instrumental....................................23

Figura 4. Cantidad de años de formación instrumental (Clarinete) ..........................23

Figura 5. Relación de la estrategia de estudio y el propósito............................25

Figura 6. Relación de la planificación con la meta....................................25

Figura 7. Planificación de objetivos de estudio.......................................26

Figura 8. Control de las metas alcanzadas............................................

Figura 9. Regulación de estrategias según la efectividad................................27

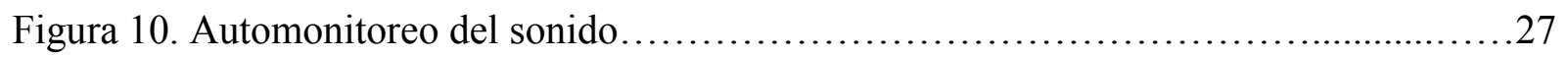

Figura 11. Automonitoreo del proceso de estudio....................................28

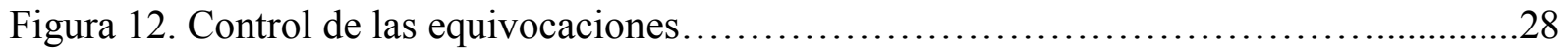

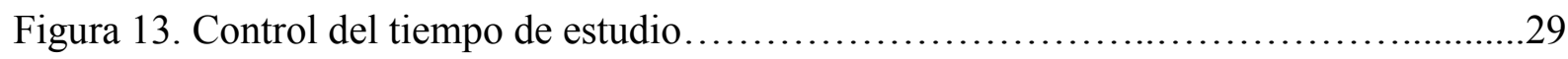

Figura 14. Autoevaluación parcial de la práctica.....................................30

Figura 15. Autoevaluación: relación objeto de estudio - interés personal....................30

Figura 16. Revisión de las estrategias de estudio....................................31

Figura 17. Autoconciencia de las estrategias de estudio...............................32

Figura 18. Autoconciencia de la capacidad resolutiva de errores........................33

Figura 19. Autoconciencia de la capacidad de comprensión de consignas........................34

Figura 20. Autoconciencia de errores............................................. 34

Tabla 1. Estrategias metacognitivas aplicadas al estudio del clarinete.....................40 
Figura 21. Síntesis de las entrevistas a docentes de clarinete..........................42

Tabla 2. Estrategias metacognitivas aplicadas al estudio del clarinete verbalizadas por clarinetistas en formación de nivel inicial y nivel medio.................................................46

Figura 22. Estrategias verbalizadas por clarinetistas en formación.....................................47 


\section{Capítulo 1}

\section{Introducción e información general}

"Sólo el conocimiento que llega desde dentro es el verdadero conocimiento".

Sócrates (Atenas, c.469 a. C. - 399 a. C.)

El presente trabajo está centrado en analizar el grado de autorregulación que poseen clarinetistas en formación independientemente del nivel de dominio en la ejecución del instrumento y /o tiempo de formación musical-instrumental. La autorregulación puede vincularse con rasgos metacognitivos. Flavell (1983), definió la metacognición como autoconciencia y control de los procesos cognitivos. Estos rasgos figuran también en la Teoría Triárquica de la Inteligencia (The triarchic mind) elaborada por Robert Sternberg (1985), quien postula en el mundo interno la existencia de componentes y metacomponentes a los que cabe la función de autorregulación.

La información sobre el nivel de conocimiento y de aplicación de estrategias metacognitivas de un clarinetista en formación y su ejecución en las sesiones de estudio, puede aportar datos de interés sobre el proceso de aprendizaje para analizar la ejecución como resultado final.

Ejecutar un instrumento musical implica la adquisición de competencias motoras, socioafectivas y cognitivas. En el caso de los instrumentos de viento, específicamente el clarinete, las competencias motoras involucradas abarcan desde el control del aire en la emisión para lograr el sonido, la memoria motriz para digitar las diferentes notas musicales hasta el 
posicionar el labio de una u otra forma para corregir la afinación. La combinación de estas competencias permite una performance de estudio y ejecución exitosa que excede la repetición como base estratégica del estudio instrumental, lo que hace necesario recurrir a teorías que conduzcan a una visión integral, donde el alumno se conciba a sí mismo como principal actor del proceso de aprendizaje y creador de estrategias que mejoren su rendimiento.

La presente investigación queda estructurada en seis capítulos. En el primero se realiza una introducción general, en el segundo se formulan tres hipótesis con diferente grado de generalidad, los objetivos y la metodología. En el tercer capítulo se explican los orígenes, antecedentes y desarrollo de la metacognición, incluyendo tanto las contribuciones de Flavell y sus continuadores, como aportes de la teoría triárquica de la inteligencia de Robert Sternberg en la que se analizan tres tipos de inteligencia (analítica, creativa y práctica) y los procesos cognitivos implicados. El cuarto capítulo comienza con la descripción de la utilización de estrategias metacognitivas por parte de los actores en situaciones de enseñanza-aprendizaje. En esta sección se incluyen las descripciones generales y la importancia de esta modalidad educativa como una perspectiva superadora. Continúa este apartado con el análisis del aprendizaje musical desde la mirada metacognitiva, incorporando una síntesis de las conclusiones de la investigación de Rafael García Martínez realizada en el año 2011 acerca de los procesos y herramientas que se ponen en juego en el aprendizaje de un instrumento, destacando el rol del alumno como generador de sus propias herramientas de resolución de problemas, surgidas a partir del pensamiento metacognitivo. En el quinto capítulo figuran las hipótesis de trabajo en las que se postula que un estudiante de clarinete mejora su performance cuando se apropia de herramientas y puede analizar su proceso de aprendizaje 
independientemente de la etapa en que se encuentren. La metacognición de los alumnos y la práctica musical reflexiva depende de la estimulación del docente. En el mismo capítulo se describen las metodologías empleadas en las experiencias de estudio. Quedan plasmados en este apartado los resultados del análisis de las estrategias metacognitivas de instrumentistas en formación, tendientes a un estudio eficaz del instrumento, basadas en la autorregulación. Se incluyen resultados de auto informes. Posteriormente se analizan estrategias metacognitivas desde el rol docente y se concluye con las identificadas a partir de las observaciones de una sesión de estudio instrumental (clarinete): prueba de pensamiento en voz alta.

El trabajo finaliza con una conclusión que sintetiza las ideas expuestas y sugiere alternativas en la práctica instrumental del clarinete. 


\section{Capítulo 2}

\section{Hipótesis, objetivos y metodología}

\section{Hipótesis principal}

El estudiante de clarinete logra una ejecución más ajustada cuando consigue apropiarse de las herramientas metacognitivas que le permiten tomar conciencia y controlar los procesos orientados a un estudio eficaz.

Los clarinetistas en formación, independientemente de la etapa en que se encuentren, son capaces de analizar reflexivamente su proceso de aprendizaje cuando se les solicita. Esto muestra el carácter autorregulador. La metacognición y la teoría triárquica de la inteligencia permiten identificar las estrategias más adecuadas al momento de la práctica instrumental.

\section{Hipótesis auxiliares}

i. Los estudiantes de clarinete pueden reconocer sus estrategias de estudio a lo largo del trayecto de formación musical-instrumental.

ii. El docente de clarinete que estimula la capacidad reflexiva de sus alumnos al momento de la práctica instrumental contribuye al despliegue de los metacomponentes.

iii. El clarinetista en formación puede centrar las sesiones de estudio en la autorregulación y la autoevaluación. La identificación de las estrategias de estudio y su posterior verbalización es proporcional al nivel de experticia. Cuanto más alto el nivel, mayor el número de estrategias que puede identificar y manifestar en voz alta el ejecutante. 


\section{Objetivo general}

Analizar las estrategias metacognitivas que utilizan estudiantes de clarinete durante el proceso de formación, la ejecución musical, la interacción con el maestro, y la influencia de la intervención docente en el desarrollo de dichas estrategias. ${ }^{1}$

\section{Objetivos específicos:}

i. Del proceso de formación. Analizar la relación de los metacomponetes y del conocimiento metacognitivo con la actividad instrumental.

ii. Del rol de la intervención docente. Indagar las estrategias didácticas que utilizan los maestros de clarinete en la práctica desde la perspectiva de la metacognición.

iii. De la ejecución instrumental. Detallar las estrategias metacognitivas identificadas durante la ejecución instrumental de clarinetistas en formación, mediante la confrontación de dos casos y el análisis estadístico de encuestas.

\section{Metodología}

Se aplicará una aproximación fáctico-empírica en un estudio combinado cualitativo y cuantitativo.

Instrumentos:

i. Encuesta de tipo autoinforme.

ii. Entrevistas personales y observaciones directas.

iii. Registro en formato video de una sesión de estudio, solicitando a dos alumnos la descripción verbal de las acciones que realizan cuando se ejercitan con el instrumento (clarinete): prueba del pensamiento en voz alta.

\footnotetext{
${ }^{1}$ Los enunciados en el cuestionario de autoinforme reflejan la conexión de esta actividad con la subteoría componencial: la planificación, el control y la evaluación.
} 


\section{Capítulo 3}

\section{La metacognición}

En el siguiente capítulo se exponen en forma general conceptos claves en el desarrollo del aprendizaje. Sin bien no fueron elaborados específicamente para el área de instrucción musical, puntualmente para la enseñanza de un instrumento como el clarinete, resultan transferibles.

Diversos estudios e investigaciones reflejan la necesidad de focalizar la atención en el modo de instruir y de estudiar para optimizar el proceso de adquisición de los conocimientos, resaltando la importancia que ocupa la actividad metacognitiva. En relación con la metacognición, Heit (2011) cita a Mateos (2001) quien afirma:

(Es) el conocimiento que uno tiene y el control que uno ejerce sobre su propio aprendizaje

y, en general, sobre la propia actividad cognitiva. Se trata de 'aprender a aprender'

facilitando la toma de conciencia de cuáles son los propios procesos de aprendizaje, de

cómo funcionan y de cómo optimizar su funcionamiento y el control de esos. (p.16)

La metacognición - término acuñado por John Flavell- resalta la importancia tanto del conocimiento del sistema cognitivo, como la de los procesos implicados y su función autorreguladora. En este contexto, explica Burón (1996): “Hay que tener en cuenta que el objetivo fundamental que indica la investigación metacognitiva es que el alumno (individuo) sea autónomo, maduro, eficaz y sepa trabajar por sí mismo” (p.136).

La Teoría Triárquica de la Inteligencia de Robert Sternberg, postula que la inteligencia se despliega en las habilidades utilizadas en la resolución de una tarea. Sternberg (1985) estudia 
la inteligencia desde tres miradas: el mundo interno, la experiencia y el mundo externo. En el mundo interno los componentes y metacomponentes son responsables de la autorregulación, aspecto clave de la inteligencia.

\subsection{Contribuciones de Flavell}

La metacognición es objeto de estudio de la Psicología Cognitiva. Para Flavell (1993) el término incluye los saberes o actividades cognitivas que regulan los procesos de adquisición del conocimiento. Burón (1996) la designó conocimiento autoreflexivo, que tiene por finalidad saber cómo, cuándo y para qué debemos usar las distintas operaciones mentales.

Si atendemos al contenido semántico del término, el prefijo meta se refiere a ir más allá y cognición a conocimiento. Cuando hablamos de metacognición hacemos referencia, entonces, a la habilidad que permite estudiar, analizar e ir "más allá" del conocimiento, indagando, evaluando y regulando los procesos implicados en las operaciones mentales.

El término metacognición, según Flavell se basa en dos principios: los conocimientos metacognitivos y las experiencias metacognitivas.

Los conocimientos metacognitivos son ideas y creencias almacenadas en la memoria a largo plazo que se utilizan según se las necesite. Se caracterizan por ser declarativos y procedimentales. Dicho conocimiento puede manifestarse en la capacidad para describir, controlar y regular eficazmente su aplicación (Flavell, 1979, 1983; Brown, 1978). Puede subdividirse en: a) conocimientos sobre las personas; b) conocimientos sobre las tareas y c) conocimientos sobre las estrategias.

a) El conocimiento sobre las personas abarca las creencias que el individuo posee sobre la cognición de los seres humanos. Así lo define Flavell (1983): “Conocimientos y 
creencias sobre diferencias cognitivas dentro de la persona, diferencias cognitivas entre una persona y otra y semejanzas cognitivas entre todas las personas, es decir, sobre propiedades universales de los procesos cognitivos humanos" (p.159).

b) El conocimiento sobre las tareas engloba, por un lado, las características de la información que se tiene y se utiliza en cualquier actividad cognitiva y por otro, las demandas de dicha actividad. Flavell (1983), sostiene: "Incluso teniendo exactamente la misma información con la que trabajar, uno ha aprendido que algunas tareas son más difíciles y tienen más demandas que otras” (pp. 159-160).

c) Los conocimientos sobre las estrategias son aquellos por los cuales identificamos los medios o acciones tendientes a lograr una determinada meta.

Según Crespo (2000) las experiencias metacognitivas aluden a reacciones o reflexiones relativamente espontáneas que ocurren antes, durante y después del proceso cognitivo, estando a disposición de las funciones que se desarrollan cuando la tarea se ha iniciado. Por ejemplo, registrar la falta de comprensión en la lectura de una frase. Esto derivará en la realización de acciones adaptativas que conlleven a lograr la lectura comprensiva, como releer la frase, pensar en ella o buscar una serie de acciones clarificadoras hasta que se logre entenderla.

En síntesis, Flavell (1979) propone un modelo de monitoreo cognitivo, con el cual estudiar las operaciones por medio de la interacción de los siguientes fenómenos: el conocimiento metacognitivo - que incluye las tareas y las estrategias - y las experiencias metacognitivas.

Flavell (1979) también habla de respuestas afectivas que se relacionan con las experiencias metacognitivas como la sensación de éxito y fracaso que pueden provocar interés o apatía. Afirma que una experiencia metacognitiva es el flujo de la conciencia que combina 
información, recuerdos y experiencias previas y que la sola evocación puede conducir a la resolución de un problema.

Como se ha mencionado, la metacognición implica pensar sobre el propio pensamiento, es un tipo de reflexión estratégica que permite regular la actividad cognitiva. Puede vincularse con la teoría del aprendizaje significativo (Ausubel, 2003) que otorga un rol activo al individuo como generador de las estrategias para aprender y descubrir soluciones a los posibles problemas que puedan surgir en el proceso de aprendizaje o en los pasos sucesivos hacia una potencial solución.

\subsection{Teoría Triárquica de la Inteligencia (The triarchic mind) de Robert Sternberg}

Robert Sternberg sostiene que la inteligencia abarca un abanico de habilidades cognitivas y no cognitivas que un sujeto utiliza cuando debe enfrentarse a la realización de una tarea. En el proceso inteligente intervienen la asimilación, la elaboración, la creación y la resolución de un problema.

Teniendo como base la teoría triárquica de Sternberg, Román Pérez y Díez López (2009) definen a la inteligencia como el conjunto de procesos realizados por la mente, condicionados por un contexto y por la experiencia propia de cada persona.

Robert Sternberg propone el estudio de la inteligencia ligada al mundo interno (subteoría componencial), la experiencia (subteoría experiencial) y el mundo externo (subteoría contextual). A continuación, se describe en forma breve cada aspecto.

La relación de la inteligencia con el mundo interno del individuo se establece a partir de los componentes o procesos intervinientes en el pensamiento. Éstos pueden ser de tres tipos: 
a. Metacomponentes: procesos de planificación, control y evaluación de la solución de un problema.

b. Componentes de ejecución: procesos de nivel más bajo que responden al mandato de los metacomponentes en la acción.

c. Componentes de adquisición del conocimiento que se utilizan para aprender a resolver un problema.

Estos componentes son independientes y se complementan. Sternberg (1985) sostiene que los metacomponentes de planificación, control, y evaluación manejan la ejecución general (componentes de ejecución) y en el mismo momento los componentes encargados de adquirir los conocimientos (componentes de adquisición) proporcionan feedback a los metacomponentes.

En la relación de la inteligencia con la experiencia individual, los tres tipos de componentes de procesamiento de la información son aplicables y varían según la experiencia de cada sujeto, haciendo que las tareas se realicen con más o menos naturalidad. Además, Sternberg (1985) refiere que al afrontar por primera vez una actividad todo parece novedoso, pero después de haber experimentado esa tarea en varias ocasiones ya resulta familiar.

Según la Teoría Triárquica de la Inteligencia, existen dos tipos de acciones importantes: el rendimiento que muestran los sujetos cuando realizan las tareas nuevas y la ejecución de las mismas. En algunos casos las tareas son sencillas, pero en otros presentan cierta complejidad, y la resolución exitosa dependerá en gran medida de la velocidad con que se ejecuten acciones previamente de carácter automático. 
Son ejemplos de la resolución de tareas que se basan en la experiencia individual la lectura comprensiva, la expresión oral, el conducir un automóvil y, a la luz del presente estudio, nos atrevemos a agregar, la ejecución de un instrumento musical. En todos los casos, sin duda, un complejo sistema de operaciones mentales fue automatizado y el accionar se realiza con el mínimo esfuerzo.

Sternberg (1985) afirma que si las tareas complejas sólo pueden ser llevadas a cabo cuando los procesos mentales implicados fueron automatizados, un fallo en dicha automatización hará que el comportamiento de un individuo sea menos inteligente, por lo tanto, se concluye que un sujeto es intelectualmente más capaz cuando ha logrado automatizar de manera óptima las operaciones implicadas en el procesamiento de la información.

Es importante destacar dos aspectos que ligados a la inteligencia desde el punto de vista experiencial: la relación que existe entre novedad y automatización y la consideración del contexto. Cuanto más exitosa sea la resolución de nuevas situaciones, más recursos cognitivos se producirán para luego ser utilizados en otras tareas de carácter novedoso. El contexto condiciona la categoría de novedosa en una experiencia, y por eso resulta difícil comparar niveles de inteligencia en diferentes grupos sociales.

La relación de la inteligencia con el contexto resalta el carácter de adaptación que además abarca la selección y modificación del ambiente. Si bien los metacomponentes y componentes que intervienen en el autogobierno mental son universales, el contexto no lo es. Las diferencias culturales condicionan las acciones que podrían ser evaluadas como inteligentes y por ello no sería justo evaluar individuos de diversos grupos sociales con un mismo test. Una evaluación válida enfoca el grado de adaptabilidad al ambiente. 
Sternberg (1985) postula que el común denominador entre las personas que desarrollan conductas exitosas es saber capitalizar (optimizar) sus fortalezas y compensar sus debilidades, adaptándose así a su ambiente y también modificándolo, maximizando su grado de ajuste.

En síntesis, la teoría de Sternberg se denomina triárquica porque postula tres tipos de inteligencia:

1. La inteligencia analítica, subteoría componencial, se relaciona con el mundo interno.

2. La inteligencia creativa, subteoría experiencial que se vincula con la experiencia.

3. La inteligencia práctica, subteoría contextual ligada al mundo externo

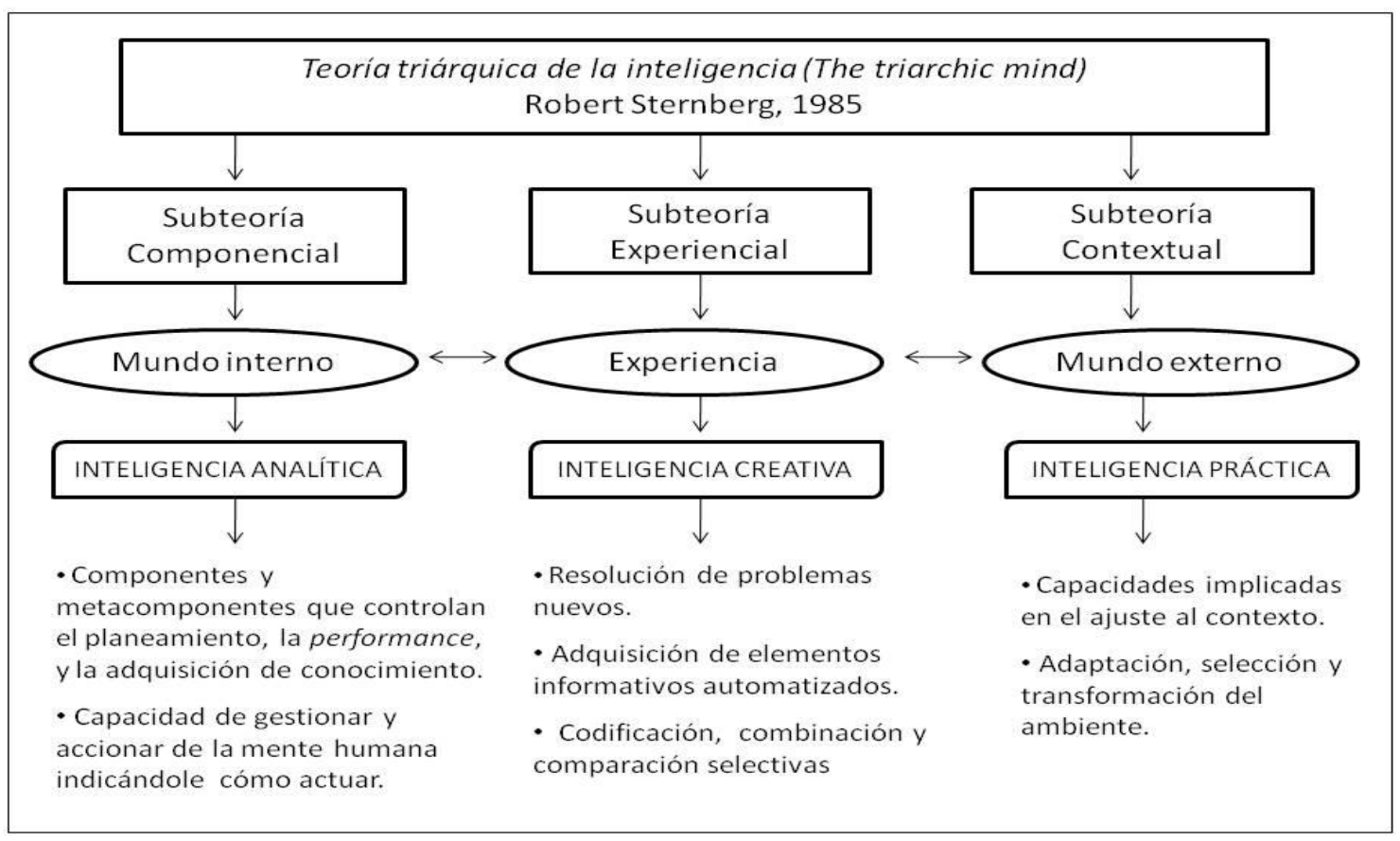

Figura 1. Síntesis de la Teoría Triárquica de la Inteligencia. Descripción de las subteorías 
En relación con la ejecución instrumental, una aplicación de la teoría de Sternberg se manifiesta en la interacción de los tres tipos de inteligencia: la inteligencia creativa se puede observar en la capacidad de variar la ejecución del músico; la inteligencia analítica está presente en el poder de desentrañar lo que el creador tuvo como idea al componer la música y la inteligencia práctica se vislumbra en la capacidad que posee el instrumentista de comunicarse con el público. Ejemplifica Sternberg (Comunicación personal, enero 16, 2016) los tres tipos de inteligencia en relación a la ejecución instrumental: "Creativa es la musicalidad. La diferencia entre Jacqueline Du Pre y todos los otros en cello [...] es su creatividad en revelar la música. Analítica en la exactitud de la comprensión de la música, lo que intentó (crear) el compositor. Práctica es la conexión con la audiencia. Algunos músicos la tienen, otros no, (manifestada en) cómo la audiencia responde". 


\section{Capítulo 4}

\section{La didáctica metacognitiva}

El aspecto autorregulador presente en el aprendizaje según un modelo metacognitivo comprende las estrategias utilizadas para la realización de tareas como la planificación, la observación y la adaptación o modificación.

Si una estrategia es algo así como un programa por el cual se procesa la información, la pregunta es: ¿Qué papel ocupan los docentes en el aprendizaje de dichas estrategias?; ¿De qué manera modifica un maestro la conducta autorreguladora de un alumno? Probablemente, la actividad metacognitiva del propio docente arroje la respuesta. Burón (1996) expone: "La metacognición de los mismos profesores es la que hace posible que tomen conciencia de qué es lo que hacen en sus mentes los alumnos y cómo, cuándo les mandan leer, estudiar, resumir, redactar o hacer un examen" (p.133).

\subsection{Estrategias metacognitivas del alumno. Aportes del docente.}

Una mejora importante en la calidad educativa incluye la enseñanza de estrategias adecuadas para la retención de los conocimientos y la apropiación eficaz de los mismos, logrando estimular y acrecentar autonomía y madurez, metas que persigue el estudio metacognitivo. Burón (1996) afirma:

El alumno que ha aprendido a aprender sabe trabajar por sí mismo y autorregular su sistema de trabajo, porque sabe autoobservar sus estrategias, comprobar la 
eficacia y descubrir nuevas técnicas sin la guía constante de otra persona. Ha desarrollado la autonomía y ha adquirido madurez metacognitiva. (pp.142 -143) Un plan que permita al alumno aprender, supone el aprender a aprender basado en estrategias motivacionales y metacognitivas.

Las estrategias utilizadas en el proceso de aprendizaje deben tener el carácter de transferibles, poder ser utilizadas en diferentes áreas.

La didáctica metacognitiva se propone el conocimiento de las diferentes estrategias, y la capacidad de discernir en qué momento utilizarlas, cual es la más adecuada para resolver una tarea. Afirma Burón (1996): “[...] el objetivo no es sólo que los alumnos conozcan qué estrategias deben usar, sino que lo más importante es que trabajen estratégicamente” (p.141). Esta acción será posible a partir de la reflexión y la autorregulación. La rapidez en la resolución dependerá del grado de automatización de las estrategias adquiridas.

El desafío del docente consiste en generar situaciones de aprendizaje donde el alumno se encuentre obligado a utilizar estrategias de resolución en forma continua, logrando hábitos de trabajo de carácter transferible.

La autonomía del estudiante, sustentada en la adquisición de estrategias adecuadas, garantiza una formación académica valiosa, que se identifica con el modelo descripto por Giuseppe Valitutti en el texto La escuela del éxito y la metacognición (La scuola del successo e la metacognizione). Valitutti (2008) rescata la conexión que existe entre el modelo de instrucción basado en la metacognición y la doctrina de Sócrates, que ubica al docente en el rol de formular una pregunta, motivar y repreguntar, dejando a sus alumnos la tarea de encontrar la mejor manera de llegar a la respuesta. Es ésta una de las más antiguas prácticas de 
enseñanza y aprendizaje, basada en la curiosidad por el saber como eje de motivación esencial.

Al hablar de la escuela del éxito, (entendida como metáfora que describe un aprendizaje óptimo y eficaz), se hace referencia a una educación cimentada en la iniciativa del alumno y en la reflexión metacognitiva. El docente, acompaña la actividad, facilita y orienta, reservándose el rol de consejero.

Otro pilar para lograr el éxito académico es la evaluación auténtica, que concibe al alumno en una perspectiva integral, descripto por Valitutti (2008):

El docente es un actor importante que tiene como misión guiar en el descubrimiento de la utilidad de las estrategias y en el progreso metacognitivo, acompañándolos en la tarea de aprender a aprender, y estimulando el desarrollo de conductas inteligentes. Explica Burón (1996): "Parte integrante de la metacognición es la capacidad de buscar estrategias y de saber usarlas; precisamente por esto, algunos autores [...] identifican el desarrollo metacognitivo con el desarrollo de la inteligencia”. (p. 138)

En esta línea, afirma Valitutti (2008): "El éxito escolar (...) se puede alcanzar a través de una serie de estrategias didácticas tendientes a valorizar el potencial de aprendizaje de cada niño (estudiante) y favorecer su autonomía". ${ }^{2}$

Bontempo (2009) agrega que el concepto de éxito escolar se amplía al hacer referencia al rol del alumno metacognitivo, indicando que es aquel que presenta una predisposición activa y responsable frente al conocimiento, creando su propio bagaje intelectual a través de preguntas, investigaciones y situaciones problemáticas.

Traducción de la tesista 
Un alumno metacognitivo hace uso eficaz de estrategias que le garantizan la adquisición de conocimientos, y una vez seleccionada la estrategia más útil y apropiada y sabiendo en qué momento utilizarla, se produce lo que identificamos como el acto metacognitivo. Dichas estrategias, según Bontempo (2009) se podrían resumir en cuatro: estrategia de selección, estrategia de organización, estrategia de elaboración y estrategia de repetición.

1. Estrategia de selección: incluye la elección de la información que se considera importante para retener. Ejemplos: seleccionar ideas centrales, subrayar conceptos importantes, leer resúmenes.

2. Estrategia de organización: involucra las conexiones de varios fragmentos de información que se están aprendiendo y los organiza dándole un orden lógico. Ejemplo: mapa conceptual.

3. Estrategia de elaboración: implica la conexión entre la nueva información adquirida y la que ya se posee. Es una de las estrategias más eficaces porque permite establecer lazos de unión entre diferentes conocimientos, los de carácter nuevo y los anteriores.

4. Estrategia de repetición: como su nombre lo indica, se basa en repetir los conceptos en la propia mente a través de palabras, sonidos o imágenes sobre la información hasta adueñarse de ella. Repetir varias veces una actividad mental relacionada con una nueva información, concluye en una memorización efectiva de nuevos conceptos.

\subsection{El aprendizaje musical desde la mirada metacognitiva}

García Martínez (2010) ha realizado una investigación sobre la relación existente entre el aprendizaje musical y la regulación metacognitiva basada en la utilización de estrategias de 
esta índole. Plantea una hipótesis general, donde afirma que los alumnos que aprenden a tocar instrumentos musicales optimizan sus prácticas de estudio a partir de la utilización de estrategias metacognitivas. Éstas constituyen una herramienta fundamental para lograr una mayor efectividad en las demandas de la preparación de las obras que exigen los currículums académicos.

García Martínez (2010) expone en la hipótesis de su investigación, que tanto el grado de conocimiento metacognitivo como el nivel de regulación metacognitiva de los alumnos que estudian un instrumento musical, pueden ser predictores del rendimiento y agrega que los sujetos con altas calificaciones presentan alto nivel metacognitivo.

En su tesis doctoral García Martínez (2010) plantea como objetivo principal identificar las estrategias que utilizan los estudiantes de veinte instrumentos diferentes en diversos conservatorios españoles y para ello utiliza dos instrumentos de medida: el cuestionario de autoinforme y la prueba de pensamiento en voz alta (think aloud). Dichos instrumentos son utilizados en la comprobación de los siguientes ítems: a) la actividad metacognitiva de los alumnos, b) sus niveles de regulación en la actividad y c) los procesos que intervienen en una sesión de estudio instrumental.

El estudio de García Martínez propone la consideración de las siguientes variables en relación a la utilización de las estrategias metacognitivas: a) sexo de los sujetos; b) edad; c) cantidad de años de estudio; d) edad de comienzo de estudio del instrumento musical; y e) cantidad de horas de estudio.

Teniendo en cuenta que el instrumento de medición conocido como prueba de pensamiento en voz alta permite identificar los procesos cognitivos y metacognitivos que subyacen a tareas de diferentes áreas y contextos, se solicitó a los sujetos que detallaran verbalmente las 
estrategias utilizadas cuando estudian para poder evaluar la actividad reguladora, característica presente en la metacognición. Esta prueba ha arrojado las siguientes conclusiones:

a. La regulación metacognitiva se relaciona de manera estrecha y positiva con las calificaciones finales, ya que los aspectos que se verbalizan tienden a resaltar la capacidad de reconocer la naturaleza y exigencias de una tarea, permitiendo el monitoreo del proceso y la evaluación de los resultados.

b. Los alumnos más avanzados son a su vez los que muestran mayor verbalización. Se observa en ellos mayor regulación metacognitiva.

c. En lo que se refiere específicamente a la selección de las estrategias de estudio, los estudiantes más avanzados implementan mayor cantidad de estrategias para estudiar una misma obra, son más activos en este campo. Los cambios en la utilización de estrategias tienen más relación con la maestría en la ejecución instrumental que con la edad.

d. La intervención docente es un factor clave en la actividad de regulación metacognitiva de estudiantes de instrumentos musicales. La no detección de errores en el monitoreo como afinación, ritmo, calidad de sonido, a largo plazo acarrean limitaciones en el desarrollo musical de los estudiantes. Se sugieren en este punto investigaciones futuras.

El estudio se complementa con el autoinforme. García Martínez considera que este instrumento de recolección de datos puede aportar mejoras en el desempeño de los estudiantes.

La prueba arroja los siguientes resultados:

a. Existe una relación positiva y estadísticamente significativa entre el pensamiento 
global metacognitivo y una calificación alta de los alumnos. A partir de esta relación se puede predecir el rendimiento académico.

b. Los estudiantes que obtienen calificaciones más altas en los exámenes de instrumento, también obtienen medidas significativamente altas en metacognición.

Con respecto a la cantidad de horas de estudio versus la calidad, concluye el autor que los alumnos que más tiempo estudian son los que más se autoevalúan, aumentando la competencia musical y efectividad en la práctica, logrando un mejor rendimiento. Sugiere que los profesores insistan en una práctica musical reflexiva para desarrollar la conciencia y capacidad autorreguladora a partir de una supervisión cuidadosa tanto de los resultados como del proceso. Esta práctica sería una gran ayuda para detectar errores y hallar soluciones. 


\section{Capítulo 5}

\section{Análisis de estrategias metacognitivas de instrumentistas en formación}

En el presente capítulo se analizan los resultados obtenidos a partir de dos experiencias que tienden a ejemplificar la aplicación de la teoría triárquica, concretamente de los metacomponentes implicados en el estudio y práctica instrumental, haciendo foco en el clarinete.

Se consideran los datos derivados de dos tipos de pruebas. Por un lado, los resultados de una encuesta (cuestionario) realizada a clarinetistas en formación y por otro se transcriben las estrategias metacognitivas identificadas durante una práctica instrumental de clarinete. Para ello se utiliza la prueba de pensamiento en voz alta, test de carácter experimental donde a través de monólogos descriptivos, se expresan pensamientos y se registran conductas.

Se incluyen también las consideraciones sobre el rol del docente de clarinete, obtenidas a partir de entrevistas personales y las observaciones recogidas durante el trabajo de campo.

\subsection{El estudio eficaz del clarinete. Autorregulación}

\section{Fundamentación.}

Indagar sobre la práctica instrumental permite obtener una idea general sobre las estrategias metacognitivas que utilizan los clarinetistas en formación al momento de estudiar el instrumento. El autoinforme del tipo cuestionario personal es un recurso para recopilar datos sobre la actividad cognitiva basado en la reflexión sobre la práctica instrumental. 


\section{Hipótesis.}

Los clarinetistas en formación, independientemente de la etapa en que se encuentren, pueden analizar su proceso de aprendizaje si se les solicita. Esta reflexión permite observar el aspecto autorregulador e identificar qué estrategias pueden ser más adecuadas al momento de la práctica instrumental.

Las diferencias en el rendimiento académico dependen del uso consciente de los metacomponentes que intervienen en el pensamiento: planificación, control y evaluación.

\section{Objetivo.}

El presente estudio se propone analizar la relación de los metacomponetes en el conocimiento metacognitivo con la actividad instrumental.

\section{Metodología.}

Encuesta con variables cualitativas que describen las estrategias que utilizan los clarinetistas en formación, abarcando diferentes aspectos de la práctica instrumental (clarinete) a la luz de los metacomponentes de planificación, control y evaluación.

El autoinforme indaga el uso de las estrategias metacognitivas, sus propósitos e implementación, como así también el reemplazo por aquellas más efectivas a partir de una revisión consciente devenida del propio monitoreo. Evalúa asimismo el reconocimiento de las equivocaciones y el poder de resolución de dificultades.

\section{Sujetos.}

La muestra ( $\left.{ }^{\circ} 30\right)$ está constituida por estudiantes de clarinete, varones y mujeres a partir de 12 años de edad. Responden el autoinforme alumnos que transitan diferentes etapas de formación: principiantes, intermedios y avanzados. El 30\% se forma de manera particular y el 70\% lo hace en instituciones oficiales: Conservatorio Provincial de Música Julián Aguirre, 
Conservatorio Superior de Música de la Ciudad de Buenos Aires Astor Piazzolla y Escuela Superior de Música Juan Pedro Esnaola.

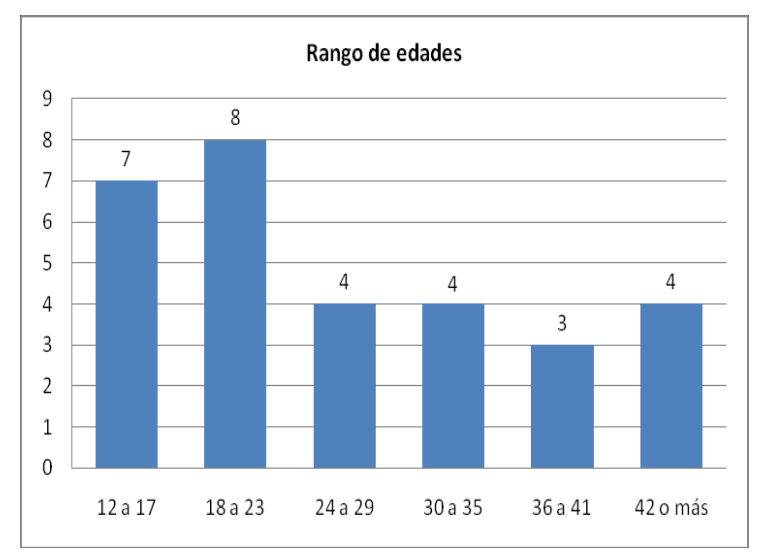

Figura 2. Rango de edades de los estudiantes encuestados.

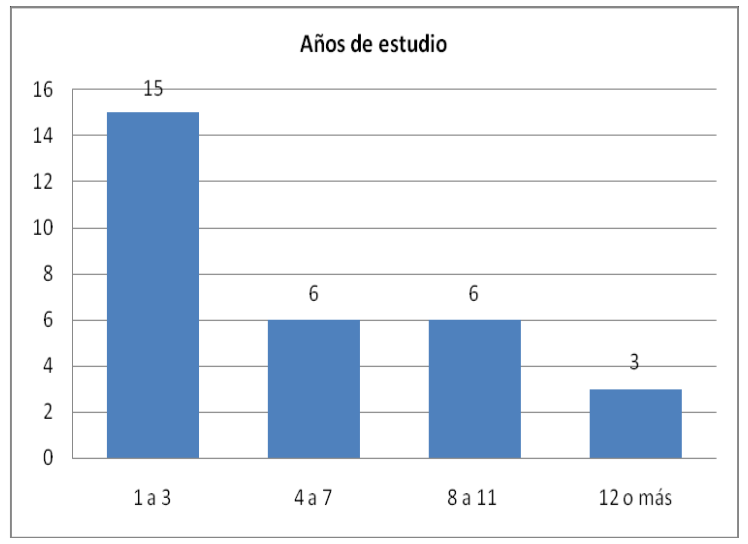

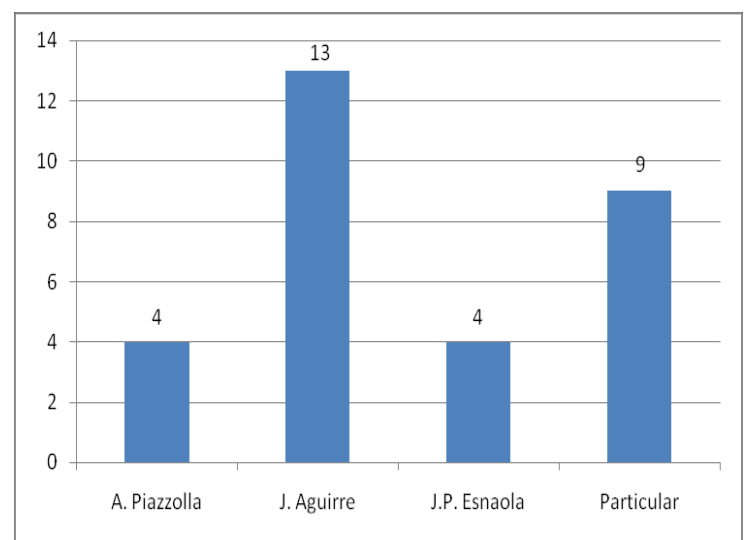

Figura 3. Instituciones de formación instrumental.

Figura 4. Cantidad de años de formación instrumental (Clarinete)

\section{Procedimiento.}

Se proporcionó a los participantes una planilla en la cual consignar la edad y el nivel académico y una lista de preguntas para ser contestadas con SI - A VECES- NO. 


\section{Resultados.}

A partir de los enunciados del cuestionario de autoinforme se recogen los siguientes resultados relacionados con el grado de planificación, control y evaluación que manifiestan clarinetistas en formación. Entendemos que estas competencias están presentes (o deberían estarlo), desde el inicio de la formación académica.

\section{De la planificación.}

Un alto porcentaje del $77 \%$ de la muestra manifiesta tener en claro la meta que se desea alcanzar en las sesiones de estudio y que la planificación consciente de las estrategias y el tiempo disponible permiten alcanzarlas.

Cuando se pregunta a los clarinetistas en formación si consideran que las estrategias que utilizan responden a lograr un fin específico en la ejecución, un 77\% responde afirmativamente.

Con respecto a la organización del tiempo para cumplir lo proyectado en cuanto al estudio, el del 56\% sostiene afirmativamente que si se planifica y un $6 \%$ manifiesta que no hacerlo. 


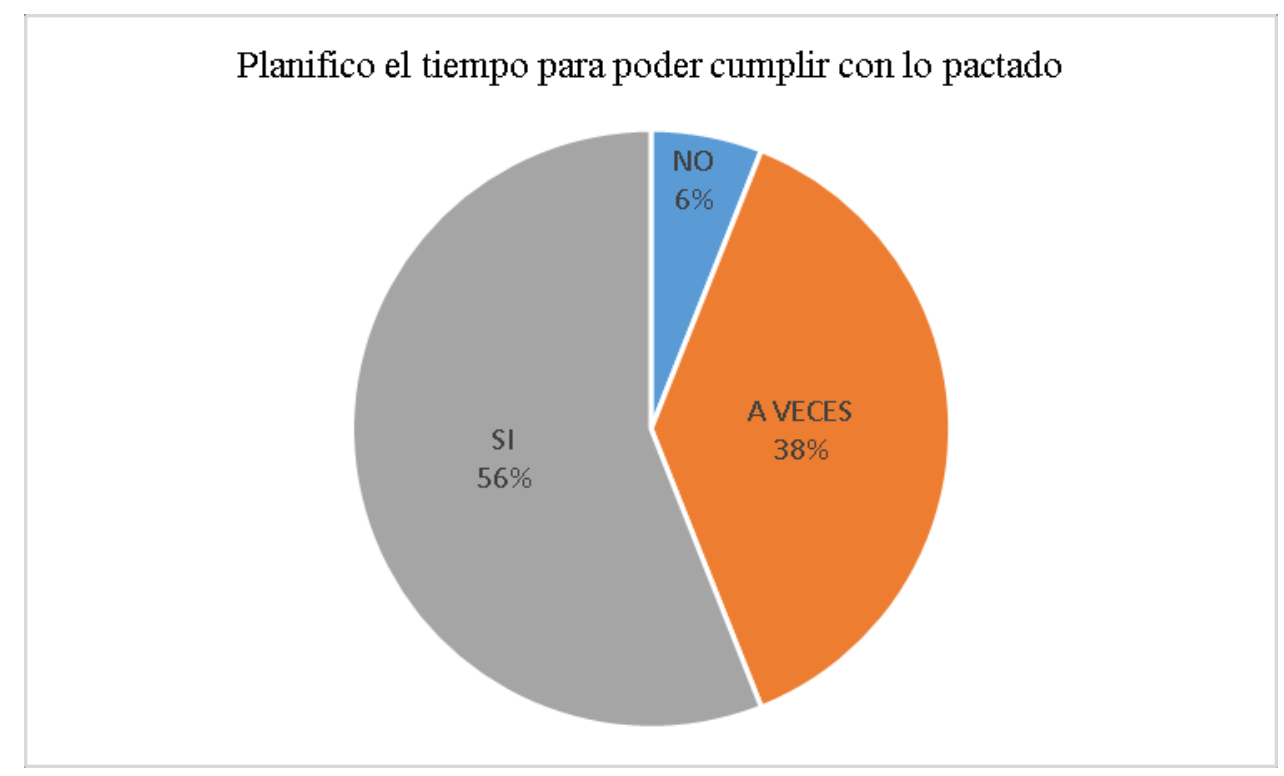

Figura 5. Relación de la estrategia de estudio y el propósito

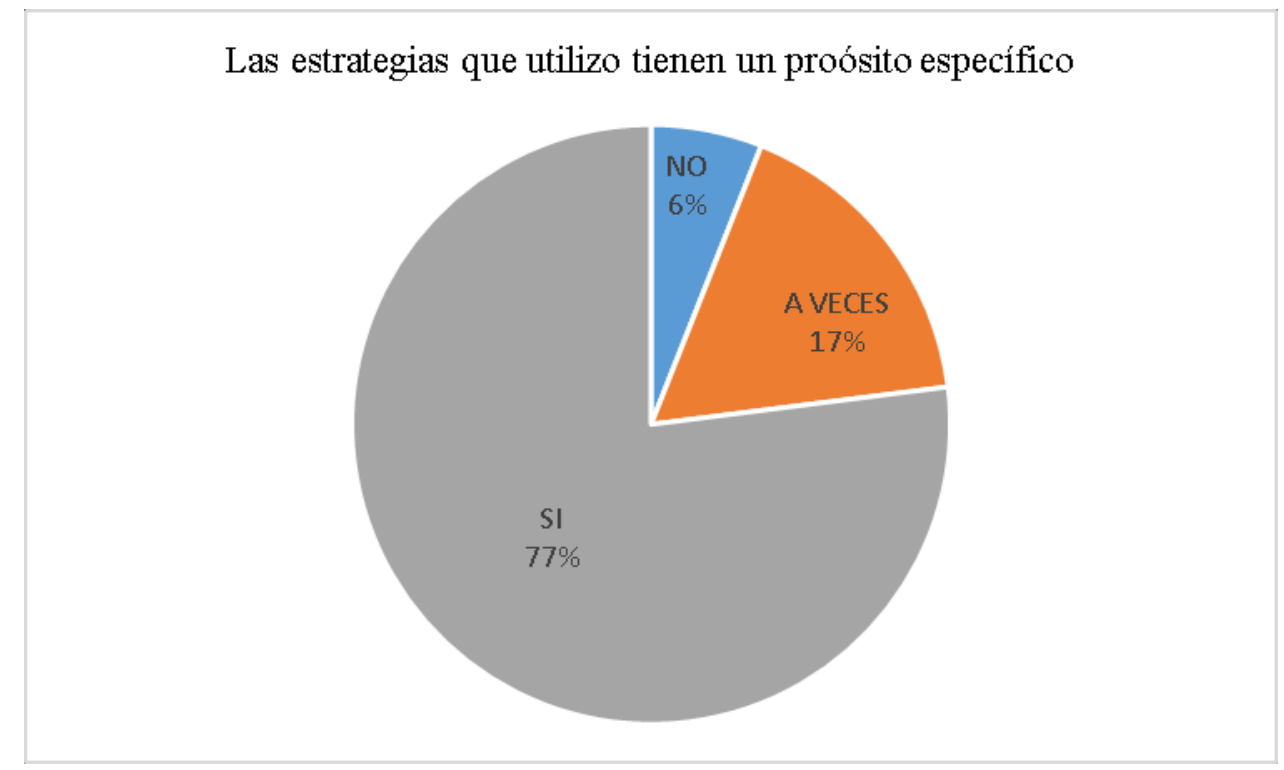

Figura 6. Relación de la planificación con la meta

Respecto del conocimiento de los objetivos, el 64\% afirma tenerlos en claro al encarar la práctica de estudio con el instrumento. 
Tengo en claro los objetivos que deseo alcanzar

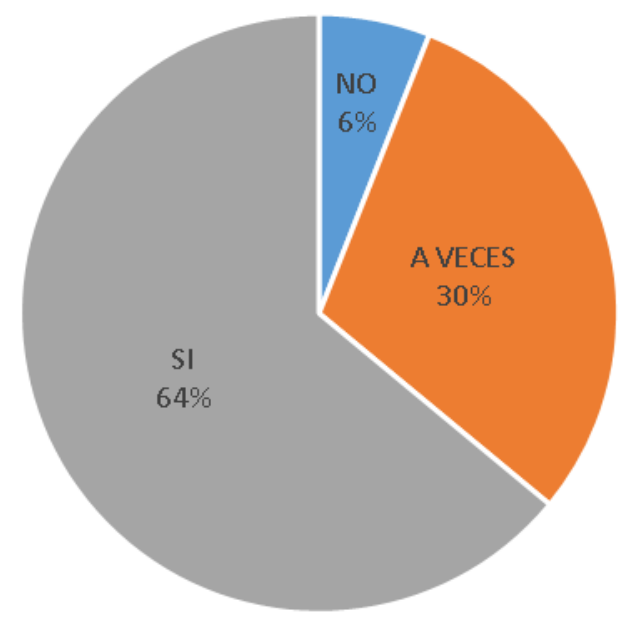

Figura 7. Planificación de objetivos de estudio

\section{Del control.}

Un 70\% de la muestra afirma advertir si va logrando sus metas. E1 57\% decide cambiar de estrategias si las utilizadas no resultan efectivas.

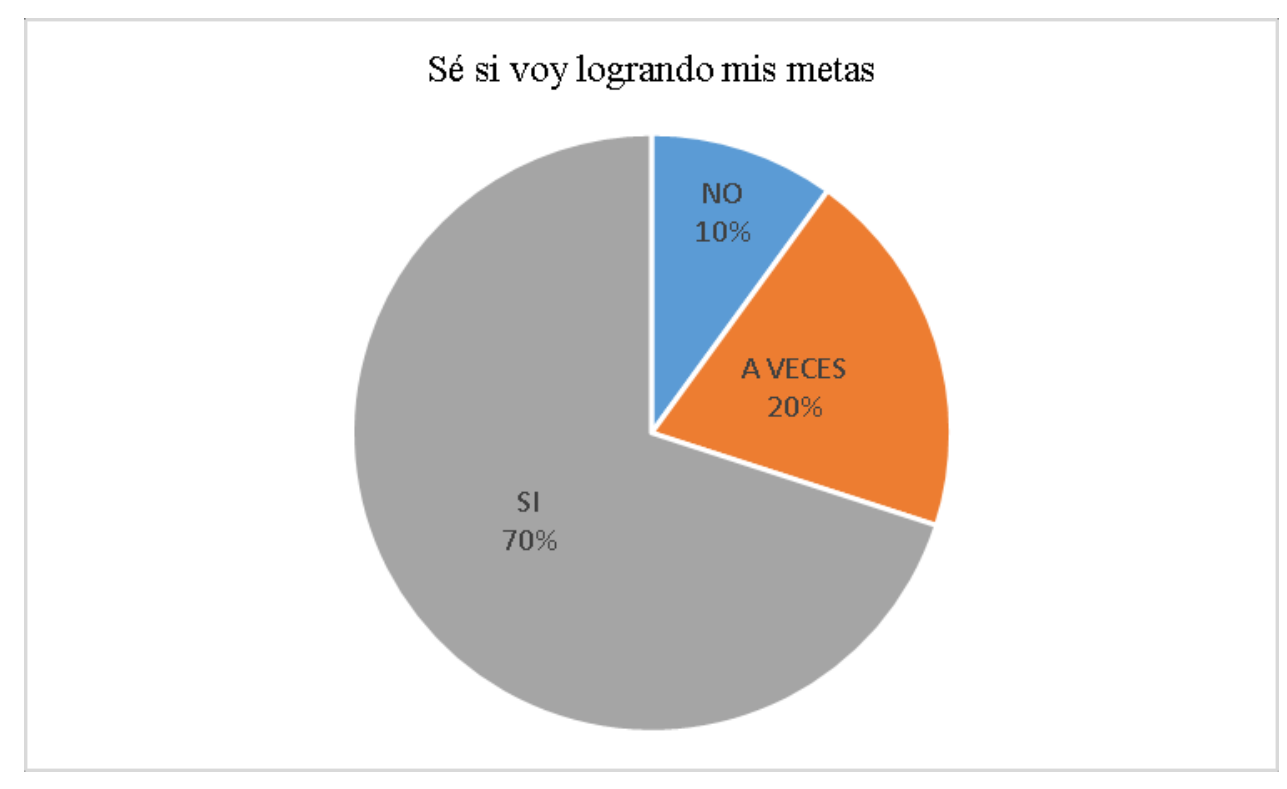

Figura 8. Control de las metas 


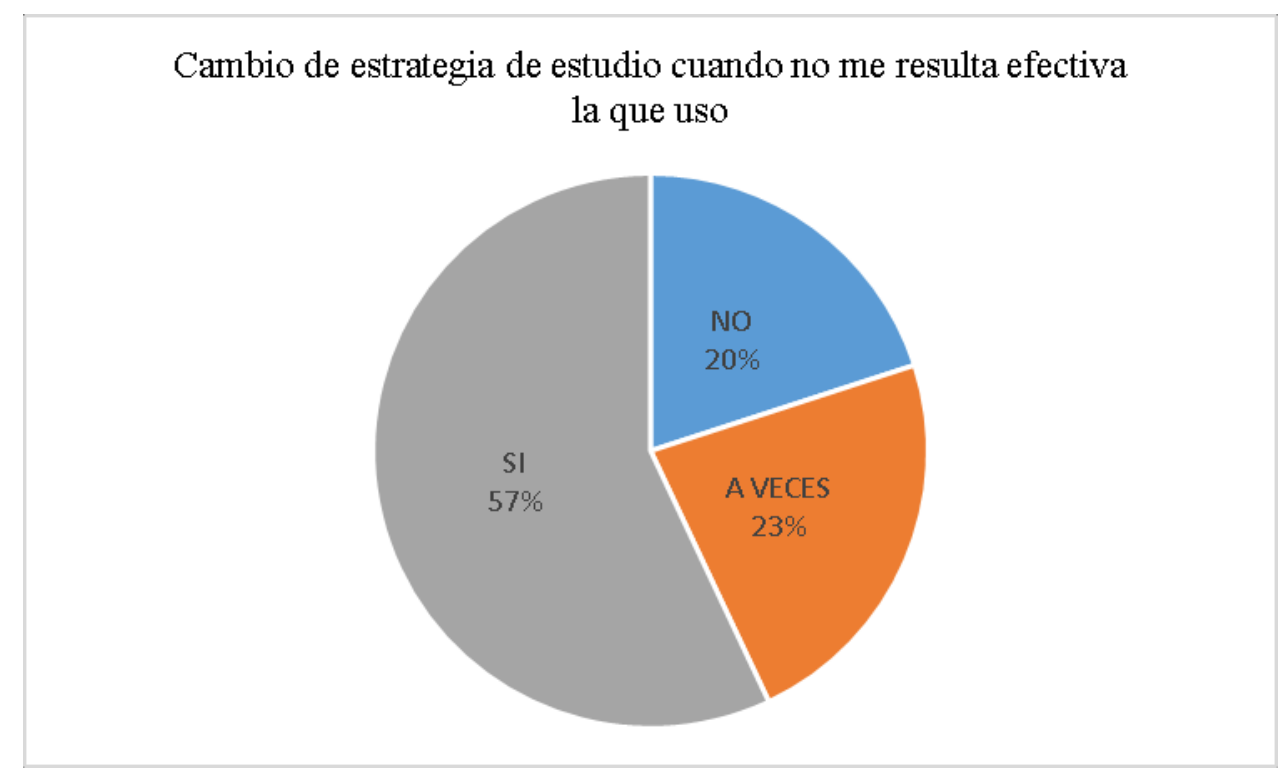

Figura 9. Regulación de estrategias según la efectividad.

El 43\% de la muestra se considera capaz de automonitorearse en forma continua durante el proceso de aprendizaje. E1 50\% afirma hacerlo a veces. Idénticos resultados se observan cuando se trata de saber cómo lograr un buen sonido con el instrumento.

Soy capaz de monitorear mi propio proceso de estudio

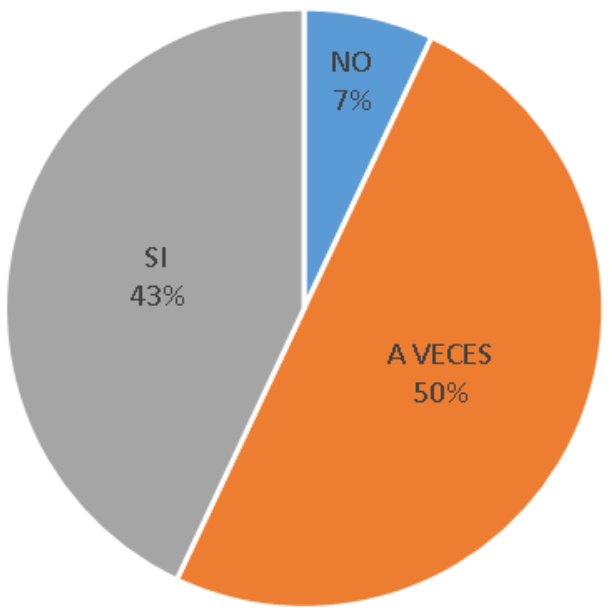

Figura 10. Automonitoreo del sonido 


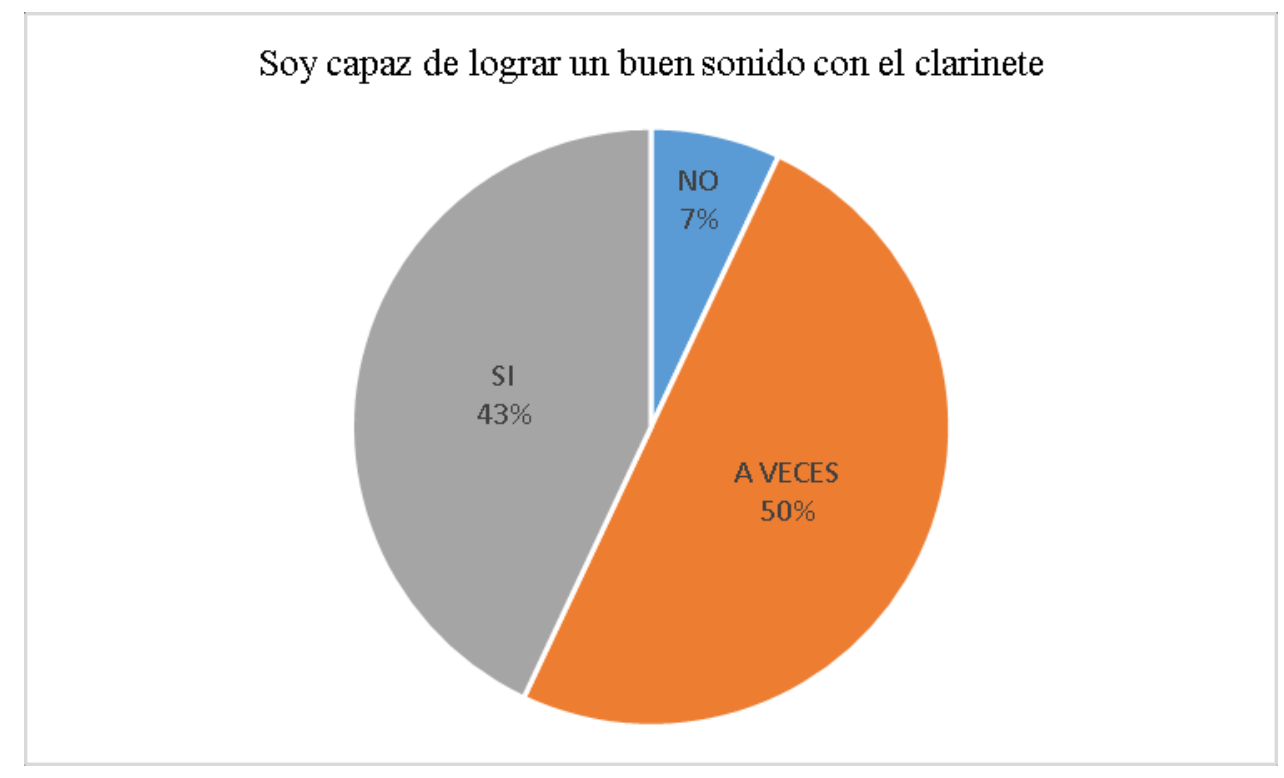

Figura 11. Automonitoreo del proceso de estudio

Cuando se pregunta a los encuestados si tienen conciencia de sus equivocaciones, un $80 \%$ las registra y sólo una minoría del $20 \%$ las registra a veces, lo cual revela un alto grado de autoconciencia.

Tengo conciencia de mis equivocaciones

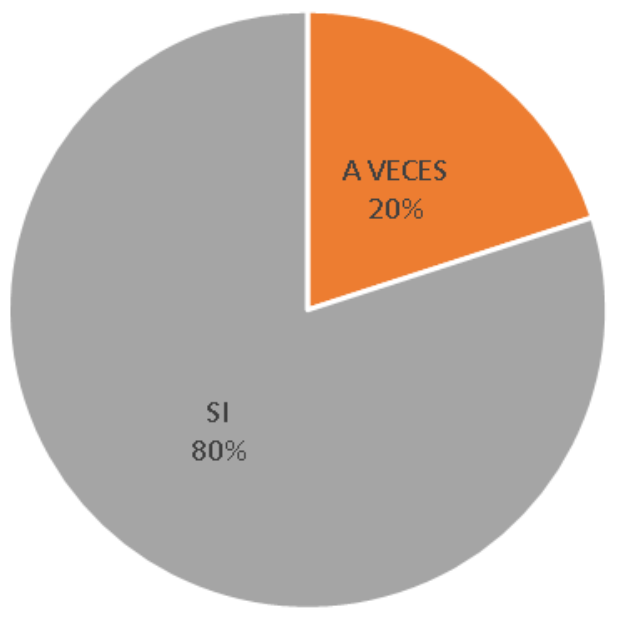

Figura 12. Control de las equivocaciones 


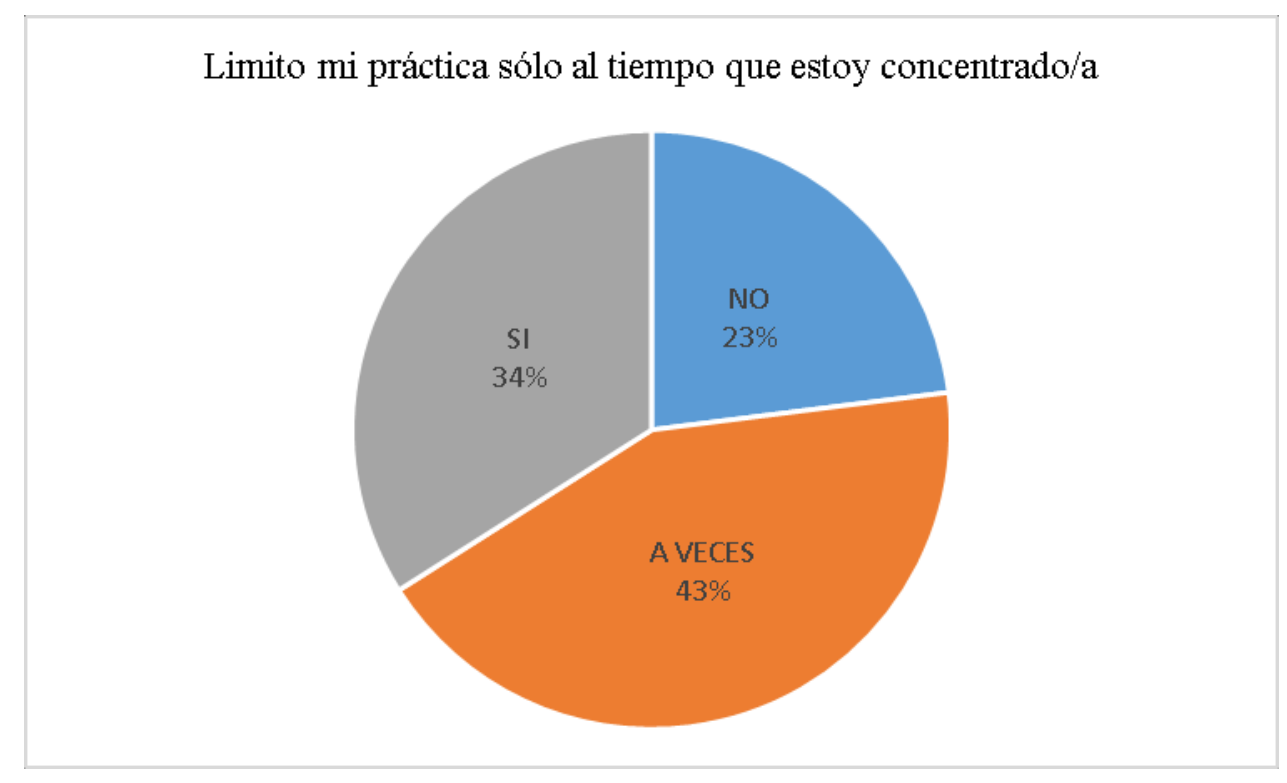

Figura 13. Control del tiempo de estudio

Con respecto a la concentración durante las sesiones de estudio, el $43 \%$ de los músicos consultados afirma que a veces limita la práctica al tiempo en el cual están concentrados. Se rescata de la experiencia que sólo el 34\% de la muestra estudia en estado de plena concentración y que el 23\% estudia aún sin registrar una concentración en su tarea, tal vez de forma automática sin revisar la práctica.

De la evaluación.

Sobre la instancia de evaluación en marcha para determinar el grado de logros obtenidos, se les consultó a los estudiantes si se preguntan luego de la práctica si han aprendido todo lo que era posible. Respondieron afirmativamente el $36 \%$, negativamente el $37 \%$ y el $27 \%$ lo hace $a$ veces. Esta indagación personal contribuye a orientar al alumno hacia un estudio más reflexivo y provechoso. 
Al finalizar la práctica instrumental, me pregunto si he aprendido todo lo que era posible

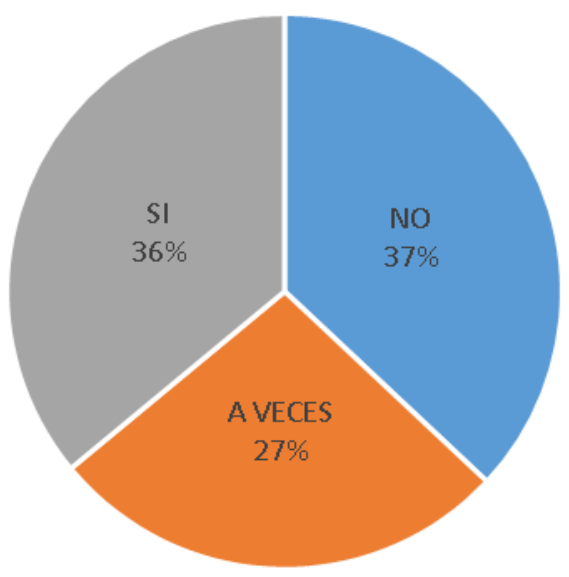

Figura 14. Autoevaluación parcial de la práctica

En lo que hace referencia a la evaluación del proceso de aprendizaje, el 36\% los sujetos reconocen aprender mejor cuando el objeto de estudio (obra musical, estudio técnico) les interesa de manera particular. Aparentemente la motivación personal funciona como elemento facilitador de la práctica.

Aprendo mejor cuando la obra o estudio técnico me provoca interés

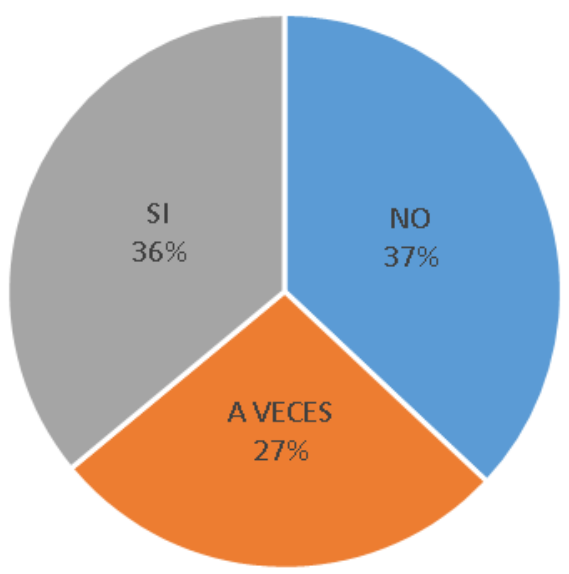

Figura 15. Autoevaluación: relación objeto de estudio - interés personal 
Cuando se indaga sobre la evaluación de las estrategias empleadas al momento de la ejercitación, la mitad de la muestra responde que tiene en cuenta este aspecto, $27 \%$ lo hace a veces y un $23 \%$ nunca lo contempla.

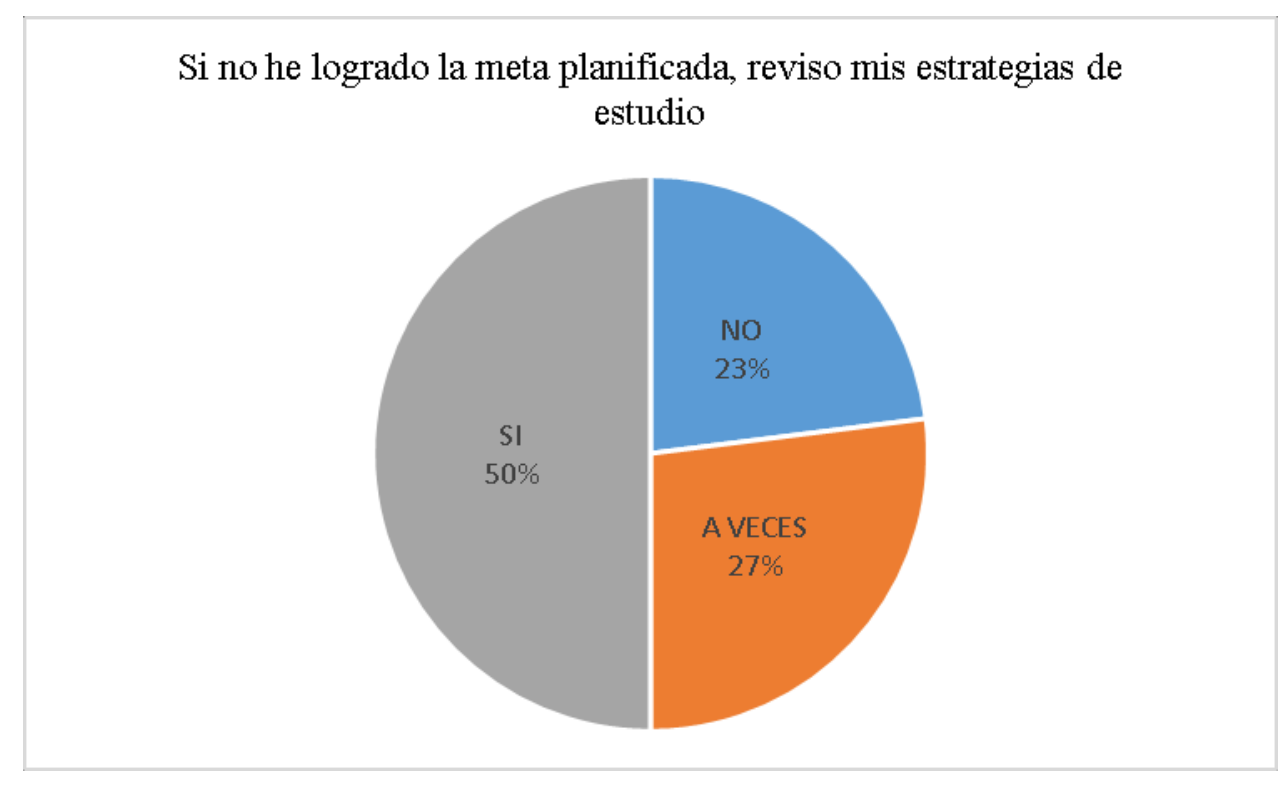

Figura 16. Revisión de las estrategias de estudio

De la autoconciencia.

Un 59\% afirma tener conciencia de las estrategias empleadas durante sus prácticas instrumentales, un $48 \%$ responde a veces y nunca lo tiene en cuenta una minoría del 3\%. 


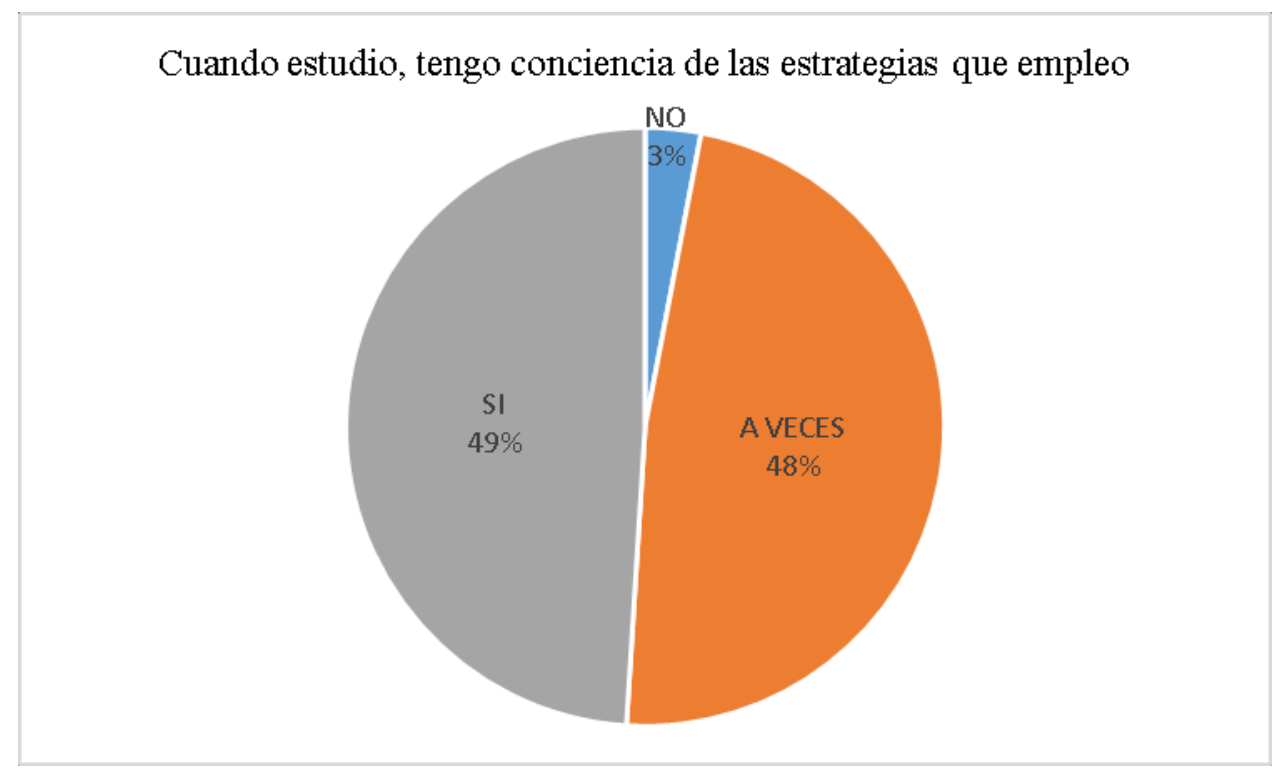

Figura 17. Autoconciencia de las estrategias de estudio

Este aspecto vincula dos variables: el nivel de autoconciencia y el nivel de instrucción (Nivel inicial N.I.: 1 a 3 años de estudio; nivel medio N.M.: 4 a 6 años de estudio y nivel avanzado N.A.: 7 o más años de estudio).

Al consultarles si son capaces de determinar el grado en que comprenden las explicaciones de los docentes y al comparar los niveles extremos, se observa que aproximadamente coinciden en las respuestas positivas en ambos casos y que la diferencia se amplía hacia una respuesta negativa cuando van avanzando los años de carrera. Los alumnos de N.A. no se juzgan tan buenos en este rasgo como los que recién se inician. Será análisis de un estudio posterior, si la razón se debe a que las explicaciones son más complejas cuando se avanza en la formación o si las respuestas positivas de los alumnos de N.I. en cuanto a la evaluación de su propia comprensión obedecen a que la autoconciencia no está plenamente desarrollada aún.

Al interrogar sobre la resolución de dificultades propias de la práctica, los de N.I. 
responden en porcentajes iguales que se consideran buenos, o a veces lo son y sólo una minoría cree no serlo. Esta variable cambia considerablemente entre los alumnos de N.A. ya que un $20 \%$ cree que son buenos solucionando estas cuestiones y un $80 \%$ a veces. En este ítem no se encontraron respuestas negativas de los alumnos de N.A.

Si bien los alumnos de todos los niveles afirman tener conciencia de sus equivocaciones, podemos observar como esta capacidad se relaciona con el autoconocimiento y es inversamente proporcional al nivel en que se encuentran. Será motivo de estudios futuros si lo que es considerado como una equivocación se da en niveles más sutiles de la ejecución y por lo tanto, más difíciles de identificar.

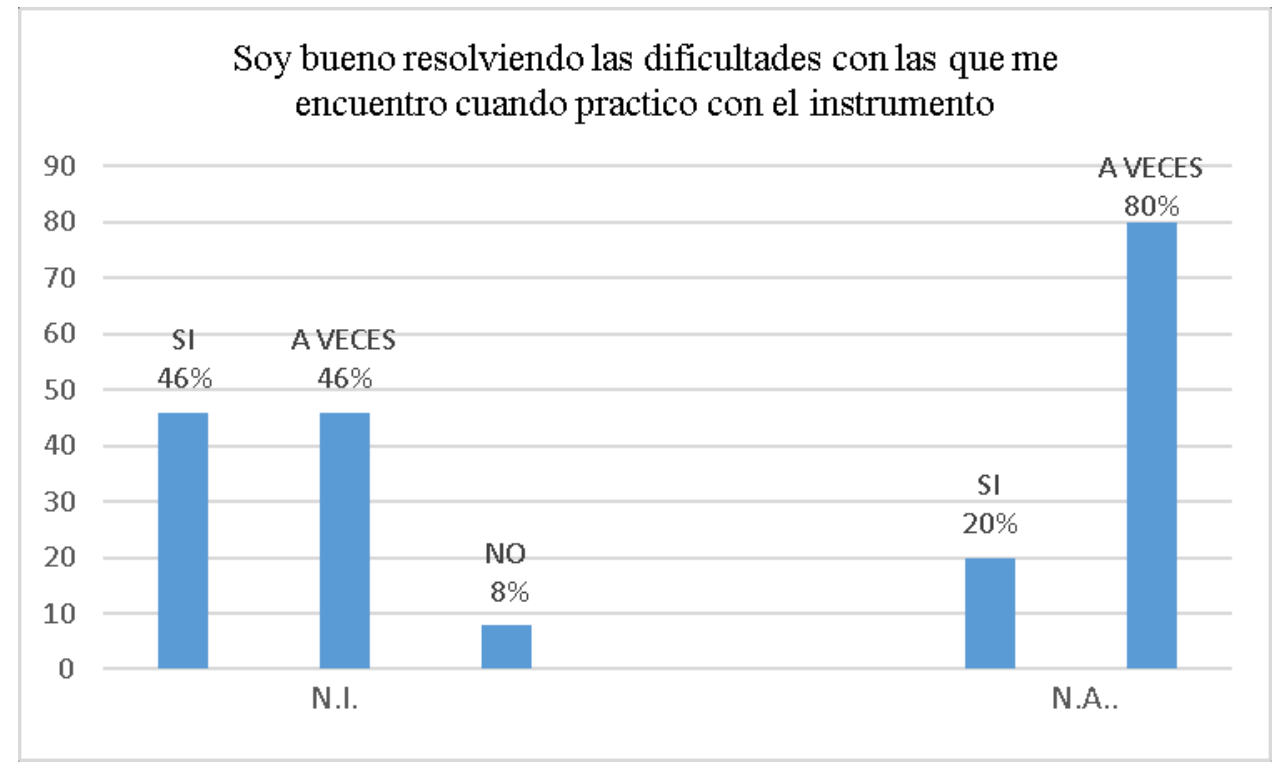

Figura 18. Autoconciencia de la capacidad resolutiva de errores 


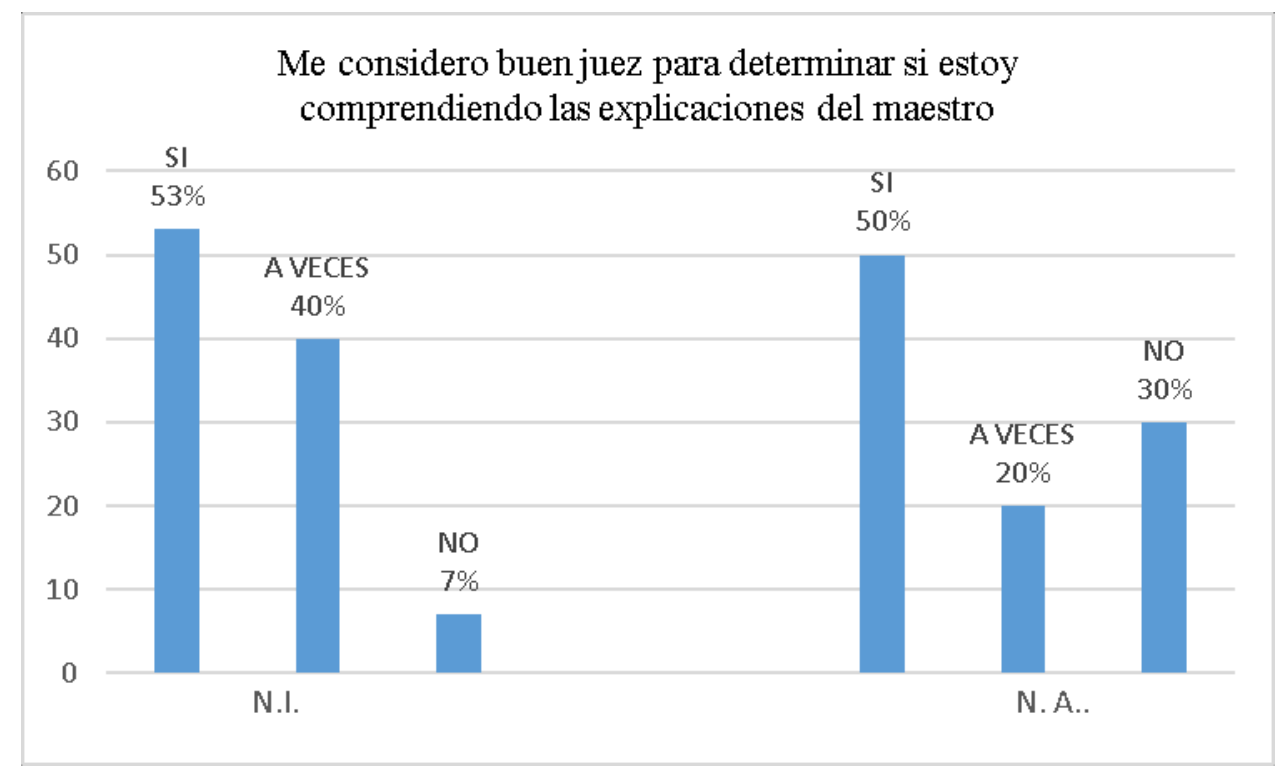

Figura 19. Autoconciencia de la capacidad de comprensión de consignas

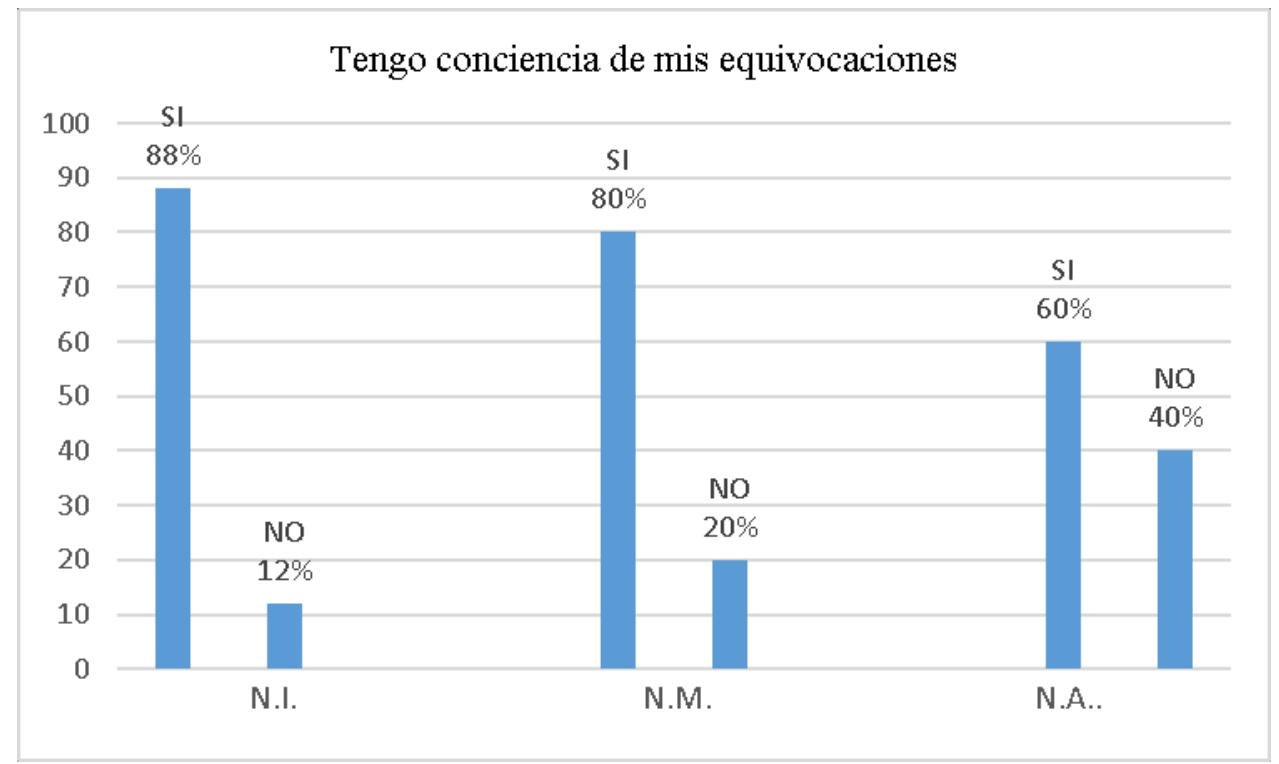

Figura 20. Autoconciencia de errores 


\section{Discusión.}

Planificar, controlar y evaluar el propio proceso de estudio utilizando diversas estrategias tendientes a la autorregulación proporciona a los clarinetistas en formación mayor independencia y eficacia en sus prácticas.

La muestra en su mayoría afirma utilizar estrategias de planificación, pero sólo a veces se sienten capaces de automonitorearse, con lo cual se infiere que el soporte del docente es necesario para la adquisición de las estrategias de aprendizaje.

En cuanto a lo que se refiere a las estrategias de evaluación se observa que sólo la mitad de los encuestados las utilizan. Sin embargo, como cierre de la práctica diaria, estimulan la autoconciencia en la adquisición de competencias, por lo que resulta interesante hacer uso de las mismas en forma diaria.

Finalmente, la autoconciencia progresa con el nivel de formación académica. Si bien los clarinetistas en formación, reflejan tendencias positivas en este sentido, los de nivel avanzado muestran una mayor conciencia de sus equivocaciones.

\subsection{El docente de clarinete ¿guía o modelo?}

\section{Fundamentación.}

El docente de clarinete cumple un papel fundamental en el proceso de aprendizaje de los instrumentistas en formación. Las estrategias didácticas que aplique el maestro inciden en la optimización de los recursos personales que permitan un avance considerable en la técnica instrumental. 


\section{Hipótesis.}

El docente de clarinete que estimula la capacidad reflexiva de sus alumnos al momento de la práctica instrumental, contribuye al desarrollo de la metacognición.

\section{Objetivo.}

Indagar las estrategias didácticas que utilizan los maestros de clarinete al momento de sus prácticas y analizarlas desde el punto de vista de la metacognición.

\section{Metodología.}

Entrevistas personales y observaciones directas.

\section{Sujetos.}

La muestra en el presente estudio está constituida por cinco $\left(\mathrm{N}^{\circ} 5\right)$ profesores de clarinete: Gaetano Russo (Italia), Luis Rossi (Argentina/Chile), Néstor Tomassini (Argentina), Emiliano Vera (Argentina) y María Florencia Battagliero (Argentina)

\section{Procedimientos.}

Se realizó una entrevista personal a cada uno de los docentes mencionados. Los entrevistados expusieron sus puntos de vista acerca de las estrategias que utilizan cuando enseñan a sus alumnos a ejecutar el clarinete y como los orientan para fortalecer la autorregulación y monitoreo.

Se formularon dos preguntas a los docentes. A partir de las respuestas se elaboraron las conclusiones que se citan en el apartado III.

1) ¿Cómo guía un docente a sus alumnos en el camino del propio monitoreo al momento de estudiar un instrumento, en este caso, el clarinete?

2) ¿Qué estrategias utiliza cuando enseña, para ayudar a sus alumnos a resolver pasajes que 
les son dificultosos en una obra musical y/o ejercicio técnico? ¿Tienden a la autorregulación?

\section{Resultados.}

Los docentes entrevistados formularon varias ideas cuando se les preguntó cómo guiar a sus alumnos en el camino del propio monitoreo al momento de estudiar clarinete. La primera idea que surgió es la de preparar al alumno para que desarrolle un estudio reflexivo, premisa metacognitiva. Así lo expone el profesor Gaetano Russo (comunicación personal, mayo 06, 2014): "Se trata de conducir al alumno hacia un estudio reflexivo". Pero él no es el único que propone la reflexión en sus clases, ya que un estudio de estas características incluye, hacer hincapié en que los estudiantes desarrollen su percepción, y en este caso prestar especial atención a la percepción del sonido propio y del sonido de otros, su calidad y fluidez. Al respecto afirma el profesor Luis Rossi (comunicación personal, junio 5, 2014): “El aprendizaje está basado en el estudio de las escalas, en el cual el profesor educa al alumno en el camino de lograr una perfección no sólo en la regularidad, sino también en el sonido y la delicadeza con que deben practicarse. Esto va desarrollando una sensibilidad y ayuda a agudizar la percepción del alumno con respecto a sus resultados".

Otros docentes entrevistados propusieron estrategias similares. El profesor Emiliano Vera (comunicación personal, febrero 16, 2015) sostiene: "Desde el inicio en el estudio del instrumento (clarinete) aconsejo y guío a mis alumnos a buscar el sonido, que les guste lo que escuchan y alternativas de emisión para alcanzar el sonido deseado. En definitiva, desde el comienzo, la autoevaluación está pautada como herramienta de estudio". Por su parte, la profesora María Florencia Battagliero (comunicación personal, febrero 23, 2015), sigue esta línea que hace foco en la percepción del sonido agregando otro aspecto relativo al valor 
estético de la producción musical cuando afirma que: “(...) hago hincapié en el correcto fraseo y la pureza del sonido (y) durante las clases les pregunto a los alumnos si les gustó como sonó."

Los modelos docentes son elementos clave para establecer parámetros de percepción que formen parte del monitoreo personal de los estudiantes El alumno debe tener con qué comparar sus producciones, su sonido. El sonido producido por del docente constituye un ejemplo para establecer comparaciones y así lo sostiene el profesor Néstor Tomassini (comunicación personal, febrero 16, 2015): “El alumno alcanza su propio monitoreo cuando puede establecer una comparación entre lo que ha estudiado y lo que escucha de su maestro, un modelo a seguir. En este caso el ejemplo del profesor es de suma importancia”.

No sólo el sonido del docente puede ser el modelo para establecer comparaciones. El profesor Emiliano Vera propone incorporar la tecnología como otro elemento que permita desarrollar la percepción, y por consiguiente favorecer la autorregulación. Propone (comunicación personal, 2015): “(...) hoy por hoy podemos incluir nuevas tecnologías, como las grabaciones o filmaciones para el análisis de los resultados. Me refiero a autograbarse".

Los maestros proponen estrategias didácticas que alientan al alumno a un estudio introspectivo. Algunos sugieren un trabajo con la práctica de escalas y la relajación muscular para mejorar la técnica instrumental e incorporar el autoregistro como estrategia de aprendizaje que permite al alumno, de ubicarse en dos roles: el de productor (productor de sonido) y el de receptor (receptor del propio sonido). Al respecto afirma Rossi (comunicación personal, junio 6, 2014): "Durante la práctica de los estudios y de las obras, ayuda mucho el grabar y luego escuchar lo que realmente uno hace. Mientras uno está involucrado en el proceso de tocar, generalmente no conserva toda la capacidad de monitorear el resultado". 
Una de las bases del aprendizaje metacognitivo es el monitoreo del propio proceso y otro aspecto es la autorregulación de las estrategias implicadas. La pregunta que surge es si se puede enseñar a los estudiantes de clarinete a autorregularse, logrando en sus sesiones de estudio la autonomía necesaria para la resolución de situaciones relacionadas a la técnica o a la expresión musical con el clarinete.

En las entrevistas realizadas, se preguntó a los docentes qué estrategias utilizan cuando enseñan para ayudar a sus alumnos a resolver pasajes que les resulten dificultosos en una obra musical y/o ejercicio técnico y si las mismas se orientan hacia la autorregulación.

Los profesores Vera y Battagliaro explican que la identificación de pasajes que presentan dificultad y la repetición con variables rítmicas o de velocidad, son dos maneras de resolver fragmentos con cierto grado de exigencia técnica. Expone Battagliaro: "Si no sale un pasaje de un ejercicio o una obra, les digo a mis alumnos que hay que marcarlo con lápiz. Si es un intervalo, se debe ejercitar de diferentes maneras, hacerlo al derecho y al revés, cambiar el ritmo, el acento y desde mi rol docente, les propongo ejercicios técnicos para pulir esa parte." (comunicación personal, Battagliaro, febrero 23, 2015). Por su parte, afirma Vera: “La propuesta es desarrollar giros melódicos (o rítmicos según sea el objetivo) que incluyan las dificultades del pasaje. Combinar rítmica y melódicamente, breves y nuevos pasajes que permitan fraccionar el trabajo de las dificultades.” (comunicación personal, Vera, febrero 16, 2015).

A modo de síntesis, en la Tabla 1 se organizan las estrategias propuestas por los docentes entrevistados según la clasificación de estrategias metacognitivas de Bontempo (2009): 


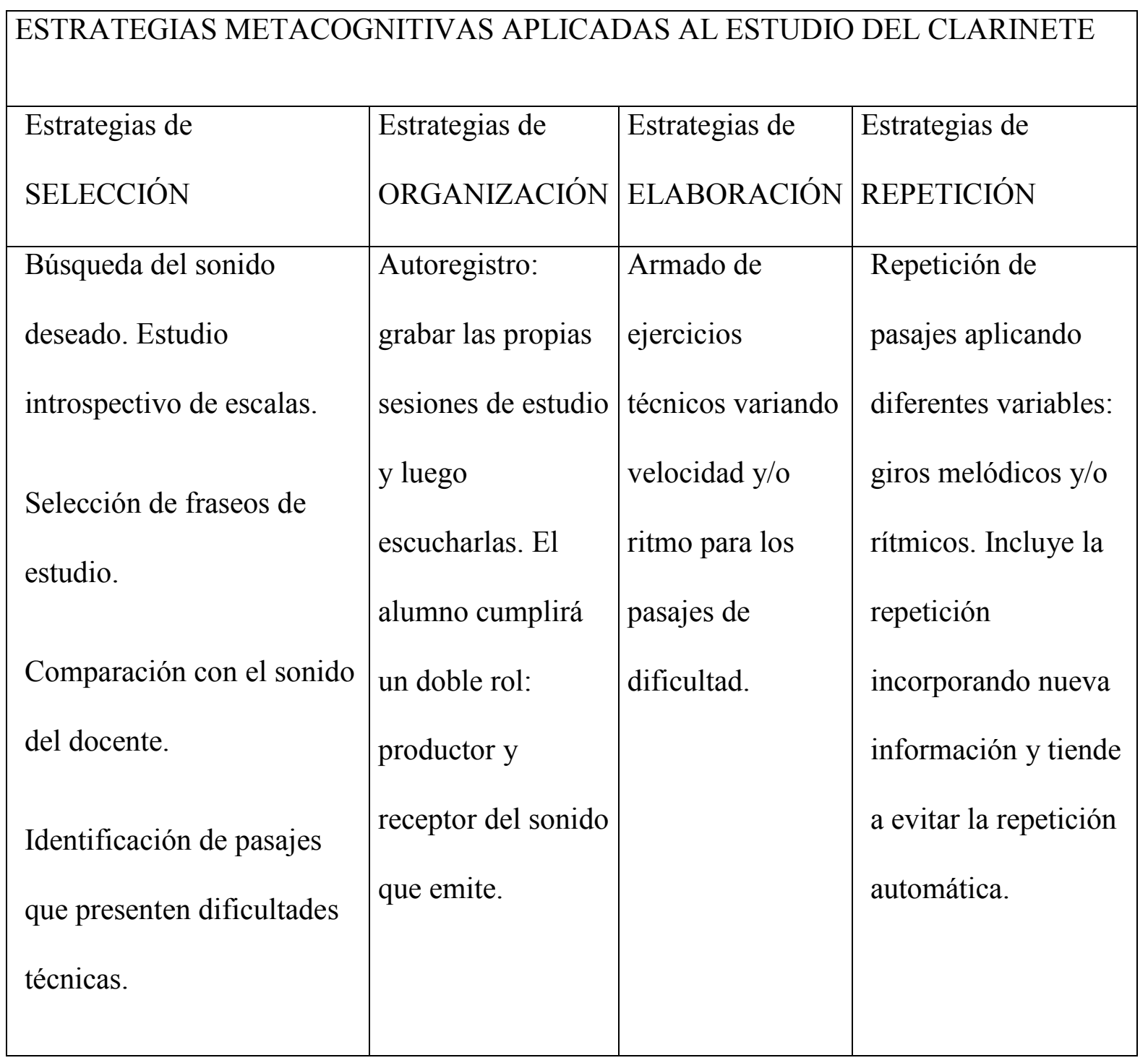

Tabla 1. Estrategias metacognitivas aplicadas al estudio del clarinete según el modelo de Bontempo (2009)

\section{Discusión.}

A partir de las entrevistas personales a los docentes de clarinete, se concluye que los mismos guían a sus alumnos hacia un estudio reflexivo que los conduce al desarrollo de la capacidad de autorregularse.

Una de las conclusiones del autoinforme a clarinetistas en formación, muestra que en la 
mayoría de los casos los alumnos no se consideran eficaces para el propio monitoreo, con lo cual el trabajo con el docente es muy importante, inclusive al punto de tomarlo como una de las estrategias de selección cuando se propone una comparación con el ejemplo didáctico que ofrece el maestro (comunicación personal, Tomassini, febrero 16, 2015). Esta premisa es corroborada desde otra área del conocimiento no específicamente musical como la neurociencia. Afirman Manes y Niro (2014):

El cerebro, como ya dijimos en el apartado anterior, también logra aprender a partir de la observación de terceros, una práctica elemental en el desarrollo de nuevas habilidades (...). Todo depende de una compleja red en nuestro cerebro que incluye las áreas de la corteza temporal, frontal y parietal y que genera, de esta manera, un entramado de acción y observación. (p.105)

Los docentes consultados enumeran una serie de estrategias de trabajo que transfieren a sus alumnos que tienden al desarrollo de los metacomponentes de planificación, control y evaluación.

Las recomendaciones pedagógicas acerca de la planificación están presentes en las indicaciones relacionadas con las estrategias de control y evaluación presentes en las respuestas de los maestros entrevistados. Esto lleva a la formación de estudiantes autónomos, capaces de autorregularse en el proceso de aprendizaje.

A modo de cierre, sostiene Gilad (2016): "Primero deberían practicar de una manera efectiva. Yo creo que la cosa sobre practicar es precisamente la disciplina de hacer cierto que todo tenga una razón, primero el por qué y después el cómo, usted tiene que razonar, usted tiene que embellecer su sonido. Es la atención hacia su trabajo y esta es la cosa más difícil 
cuando estudia". ${ }^{3}$

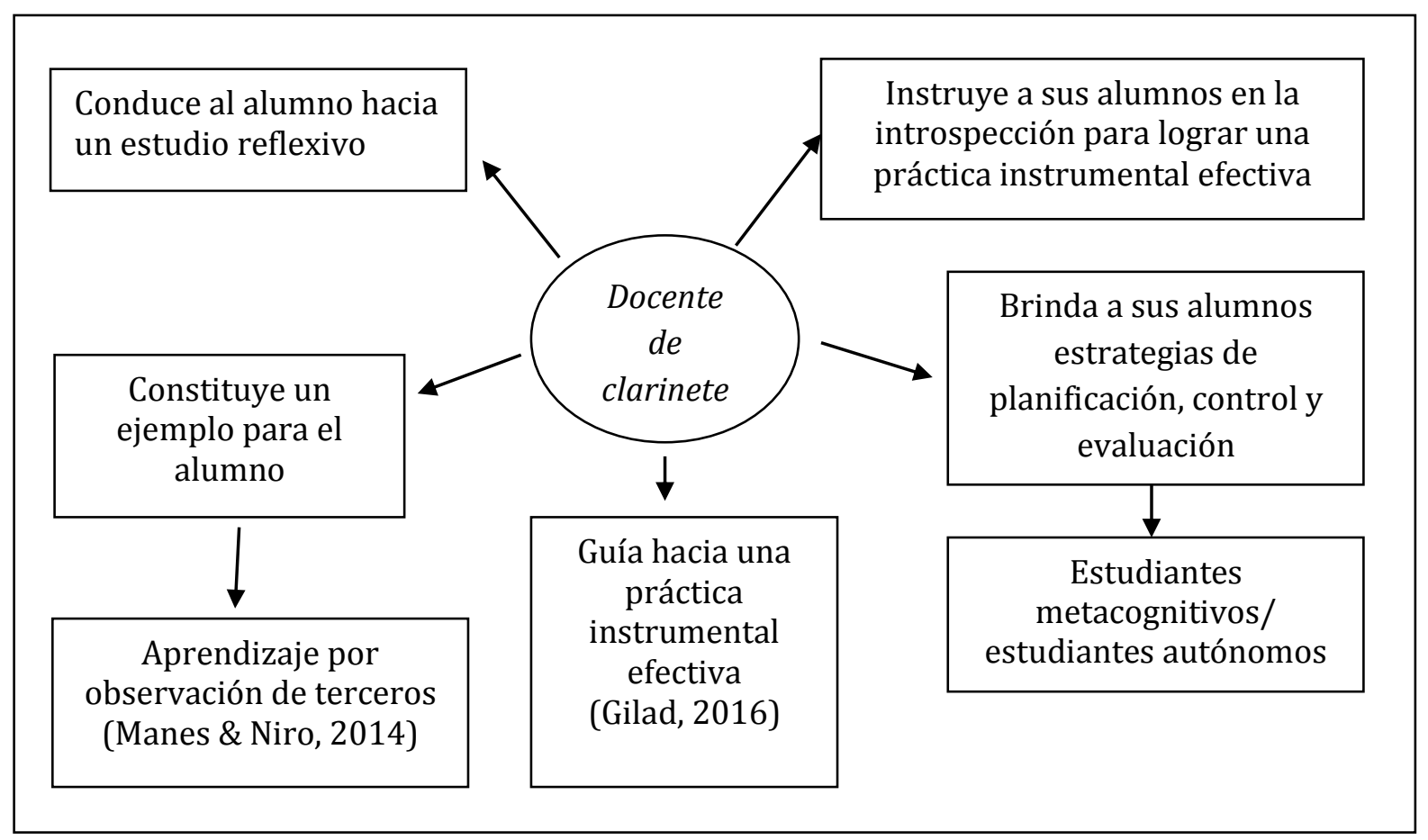

Figura 21. Síntesis de las entrevistas a docentes de clarinete

\subsection{Observaciones y herramientas metacognitivas}

\section{Fundamentación}

El autoinforme realizado a los clarinetistas en formación, muestra la utilización de estrategias metacognitivas al momento de la práctica con el instrumento, presente en todos los niveles de formación. La diferencia en el desempeño lo establece el nivel de experticia con el instrumento, que involucra no sólo el automonitoreo, sino el posterior descenso en el nivel de pensamiento de control y evaluación.

$3 \quad$ Traducción del tesista 


\section{Hipótesis}

El clarinetista en formación centra sus sesiones de estudio en la autorregulación y la autoevaluación. La identificación de las estrategias de estudio y su posterior verbalización es directamente proporcional al nivel de experticia, cuanto más alto el nivel de formación, mayor el número de estrategias de estudio que puede identificar y manifestar en voz alta.

\section{Objetivo}

Detallar y analizar las estrategias metacognitivas identificadas durante la ejecución instrumental de clarinetistas en formación. Confrontar el estudio de dos casos contrastantes.

\section{Metodología}

Estudio de caso. Registro en formato video de una sesión de estudio, solicitando a dos alumnos la descripción verbal de las acciones que realizan cuando se ejercitan con el clarinete. Como instrumento metodológico se utilizó la prueba de pensamiento en voz alta teniendo como base los protocolos ideados por Ericsson \& Simon (1993). En este caso se pidió a los alumnos que enuncien en voz alta las estrategias que utilizan cuando estudian una nueva obra musical.

\section{Sujetos.}

Dos estudiantes de clarinete del Conservatorio Julián Aguirre, de niveles de formación contrastantes: nivel inicial y nivel medio. 


\section{Estímulo musical.}

Obra musical "Surcos" (Huayno) del compositor Edgardo Benito Acosta. Corresponde aclarar que los estudiantes no han tenido contacto previo con la obra.

\section{Equipamiento.}

Filmadora digital, Trípode, Clarinete (se filmará a cada alumno con su instrumento).

\section{Procedimiento.}

Se solicitó a dos alumnos de clarinete, uno de nivel inicial y otro de nivel medio, que realicen una sesión de estudio instrumental de 15 minutos de una obra que no conocen previamente. Los clarinetistas en formación realizaron una descripción verbal de las estrategias utilizadas al momento de la práctica, cumpliendo con la consigna previamente dada para la realización del estudio.

\section{Resultados.}

Se observa que el alumno de nivel medio detalló verbalmente once estrategias de estudio y las utilizó para la lectura a primera vista de la obra propuesta:

1. Identificación de la armadura de clave inicial para identificar la tonalidad de la obra: "Miro en qué tonalidad está (la obra), la cantidad de sostenidos que tiene".

2. Identificación de pasajes que presentan dificultad rítmica a partir de la observación: “Observo pasajes con un poco más de complejidad" 
3. Identificación de pasajes complejos directamente encerrándolos con lápiz en la partitura: "Observo pasajes con un poco más de complejidad y los encierro con un círculo por la cuestión rítmica"

4. Solfeo rítmico de frases para asegurar la lectura y la posterior ejecución: "Observo pasajes con un poco más de complejidad, los encierro con un círculo por la cuestión rítmica, los practico más lento y los solfeo rítmicamente (con la voz)"

5. Digitación de la obra indicando número de llave para la posición de una nota: "Anoto el número (o letra) de la llave (en la partitura) que debo usar".

6. Repetición de pasajes que presenten dificultades técnicas. "Me detengo en algunas partes más complicadas y las vuelvo a hacer".

7. Repetición de pasajes u obra completa con cambio de velocidad: más rápido/más lento: "Observo pasajes con un poco más complejidad y los encierro con un círculo por la cuestión rítmica, y lo practico más lento". "Procedo a tocarla nuevamente, un poco más rápida".

8. Identificación/ evaluación del cambio de tonalidad en el desarrollo de la obra: "Me cuesta trabajo identificar la tonalidad (la obra)".

9. Reconocimiento de notas erradas: "me confundí la alteración”.

10. Reescritura musical de un pasaje para facilitar la lectura: "Me detengo en esa corchea con puntillo para poder entenderlo (se refiere al compás), (...) y lo voy a dibujar de otra forma así lo entiendo".

11. Evaluación del nivel de dificultad de la obra: "No tiene figuras rítmicas complicadas (células rítmicas)". "Toda esa parte la puedo tocar, es fácil. "Ahora la entiendo, no es difícil”. 
Por su parte, el alumno de nivel inicial, en condiciones idénticas al estudiante de nivel medio, logra verbalizar dos estrategias de estudio:

1. Identificación de la armadura de clave inicial para identificar la tonalidad de la obra: "Está en La".

2. Identificación del indicador de compás (numerador y denominador): "compás de $2 / 4 "$

A continuación, se presentan una tabla en donde se agrupan las estrategias de estudio enunciadas por los estudiantes de clarinete según el modelo de Bontempo (2009) y un gráfico que ilustra comparativamente, las cantidades de cada una de dichas estrategias nombradas y utilizadas durante la experiencia.

\begin{tabular}{|l|l|l|l|}
\hline \multicolumn{2}{|l|}{ ESTRATEGIAS METACOGNITIVAS APLICADAS AL ESTUDIO DEL CLARINETE } \\
\hline Estrategias de & Estrategias de & Estrategias de & Estrategias de \\
SELECCIÓN & ORGANIZACIÓN & ELABORACIÓN & REPETICIÓN \\
\hline Identificación de la armadura de & Digitación de la & Reescritura & Repetición de \\
clave inicial para identificar la & obra indicando & musical de un & pasajes que \\
tonalidad de la obra. & número de llave & pasaje para & presenten \\
Identificación de pasajes que & para la posición de & facilitar la lectura. & $\begin{array}{l}\text { dificultades } \\
\text { técnicas. } \\
\text { presentan dificultad rítmica a } \\
\text { partir de la observación. }\end{array}$ \\
Identificación de pasajes & una nota. & Repetición de \\
complejos directamente & pasajes u obra \\
encerrándolos con lápiz en la & & completa un \\
\end{tabular}




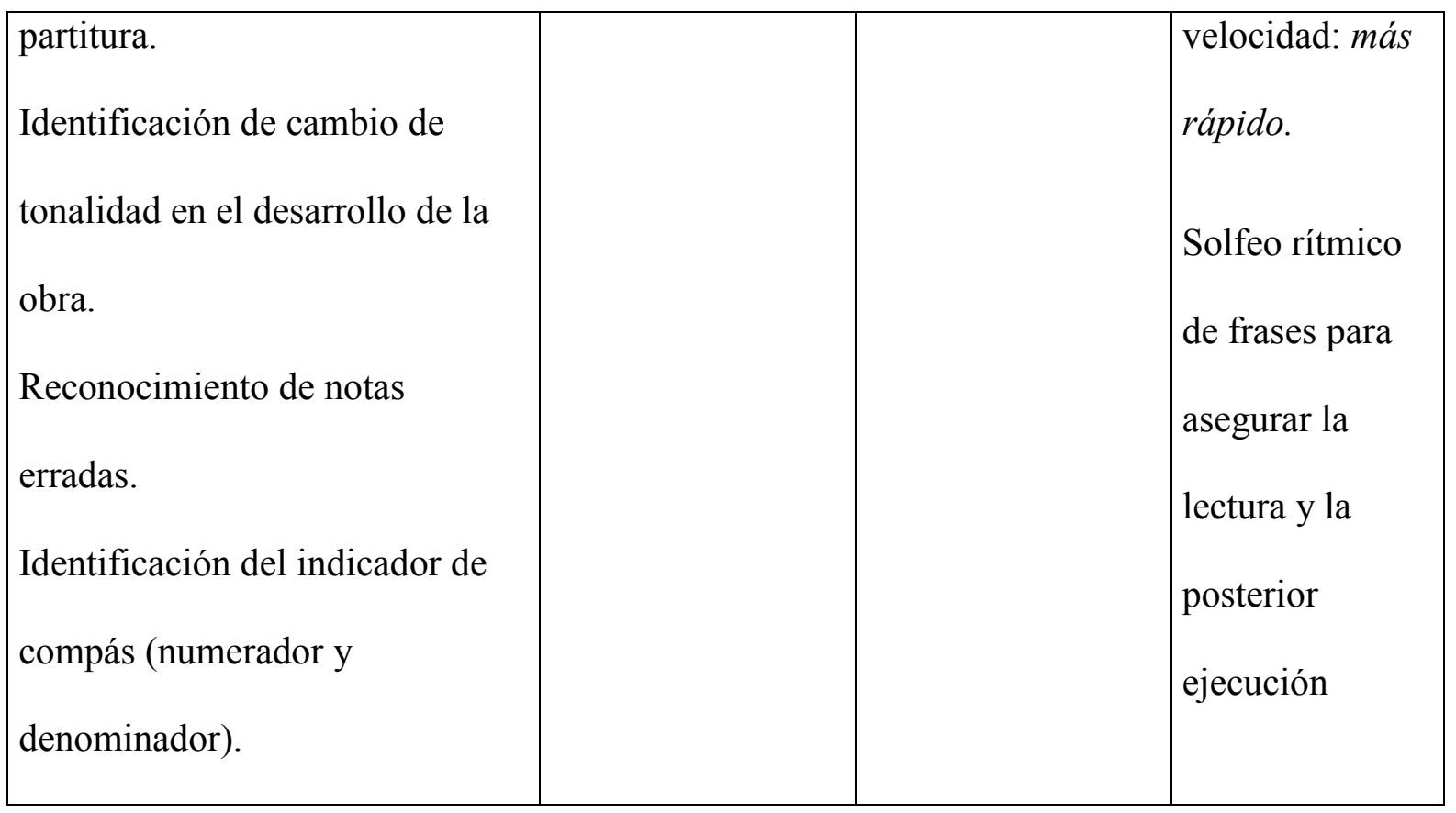

Tabla 2. Estrategias metacognitivas aplicadas al estudio del clarinete según el modelo de Bontempo (2009) verbalizadas por clarinetistas en formación de nivel inicial y nivel medio.

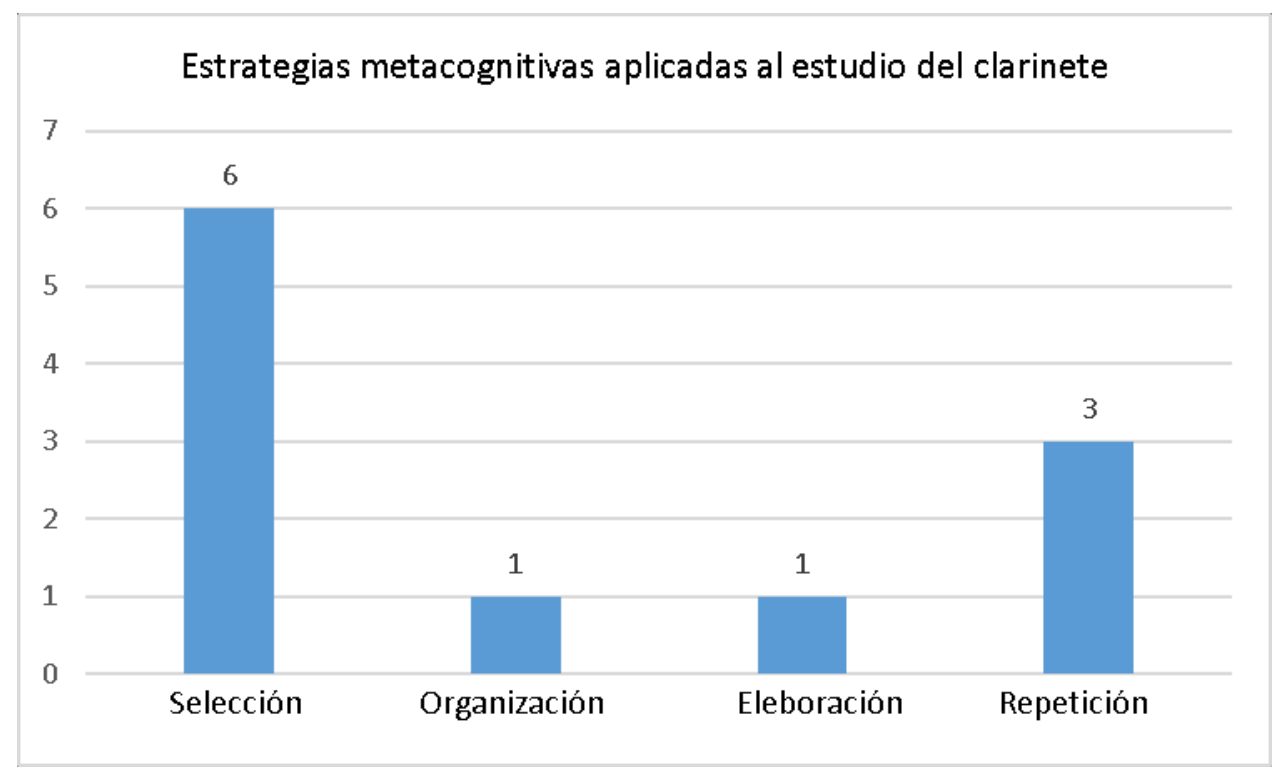

Figura 22. Estrategias verbalizadas por clarinetistas en formación 


\section{Discusión.}

A partir de los resultados obtenidos en la prueba de pensamiento en voz alta, se observa que el alumno de clarinete de nivel medio ha podido verbalizar mayor cantidad de estrategias metacognitivas de estudio, obteniendo un total de once estrategias manifestadas en voz alta El alumno de nivel inicial verbalizó sólo dos estrategias.

Según el modelo de Burón, las estrategias manifestadas verbalmente por los sujetos se clasificaron en estrategias de selección, de organización, de elaboración y de repetición; agregando a dicho modelo las estrategias de evaluación, expresadas por el clarinetista de nivel medio quien analizó el grado de dificultad la obra en general propuesta y específicamente de la parte rítmica.

Los alumnos de ambos niveles verbalizan un mayor número estrategias de identificación y en menor medida aquellas que se relacionan con las estrategias de organización y elaboración.

Se concluye que un clarinetista, a medida que avanza en su formación, aumenta su nivel de autorregulación y la autoevaluación dado que logra identificar sus propios errores, establece comparaciones didácticas entre su producción instrumental y la de otros (maestros y pares), individualiza estrategias eficientes de estudio y descarta aquellas que han demostrado ser de poca utilidad.

Será motivo de estudios futuros analizar la relación de las estrategias metodológicas del docente, su propia metacognición y su impacto en la apropiación y/o elaboración de estrategias metacognitivas por parte de los alumnos. 


\section{Capítulo 6}

\section{Discusión, conclusiones y resultados}

La presente investigación muestra la aplicación de estrategias metacognitivas en el estudio de un instrumento musical, el clarinete, a partir del control y la conciencia de los procesos de aprendizaje.

Si bien el término metacognición al que hace referencia Flavell (1993) como un proceso que incluye actividades cognitivas que regulan los procesos de adquisición del conocimiento, no fue pensado puntualmente para ser aplicado en el estudio de un instrumento musical, los procesos del modelo resultan transferibles. La metacognición se caracteriza como un intento reflexivo de adquisición del conocimiento que, como se expone en esta tesis, puede vincularse con la práctica instrumental del clarinete tal como muestra el análisis de las estrategias de estudio empleadas por el alumno y sugeridas por el docente.

Las estrategias metacognitivas se constituyen en las herramientas que utilizan los clarinetistas en formación para optimizar sus ejercitaciones y garantizar un estudio eficaz del instrumento.

Coincidiendo la investigación de García Martínez (2010), los datos de este trabajo muestran que los alumnos que aprenden a tocar instrumentos musicales mejoran sus prácticas de estudio a partir de la utilización de estrategias metacognitivas y desarrollan conductas como ejecutantes autónomos y competentes.

Los resultados del cuestionario de autoinforme (encuesta) señalan que los clarinetistas en formación manifiestan, en diferente medida, conductas tendientes a la resolución de 
problemas vinculadas con los metacomponentes presentes en la inteligencia analítica (subteoría componencial) relacionada con el mundo interno, que junto a la inteligencia creativa y a la inteligencia práctica son contempladas en la Teoría Triárquica de la Inteligencia de Robert Sternberg. Los metacomponentes consisten en la planificación, el control y la evaluación del propio proceso de aprendizaje.

La mayoría de los estudiantes de clarinete encuestados manifestaron hacer uso de estrategias de planificación. El porcentaje disminuye cuando se indaga sobre el uso cotidiano de estrategias referidas al monitoreo y a la evaluación, lo cual muestra que el control del docente es necesario para la adquisición y apropiación de las estrategias de este tipo.

A partir de entrevistas personales, los docentes consultados manifestaron guiar a sus alumnos hacia un estudio reflexivo que los conduzca al crecimiento de la capacidad de autorregularse, contribuyendo al desarrollo de los metacomponentes de planificación, control y evaluación. Como fruto de este intercambio surgió la idea de organizar y clasificar los testimonios según el modelo planteado por Bontempo (2009), quien sugiere que las estrategias de estudio podrían ser agrupadas en: estrategias de selección, de organización, de elaboración y de repetición. Dicha clasificación, detallada en el capítulo 5 puede ser considerada como un aporte a la didáctica instrumental del clarinete que promueva en los alumnos la adquisición de conocimientos a partir de la selección de la estrategia más útil y apropiada para cada situación, que se identifica como un acto metacognitivo.

De acuerdo con los resultados obtenidos se puede decir que existe una relación entre el nivel de formación académica y la capacidad de manifestar verbalmente cuáles son las estrategias que se utilizan en una sesión de práctica instrumental de clarinete. En la prueba de pensamiento en voz alta, el alumno de clarinete más avanzado logró verbalizar una mayor 
cantidad de estrategias utilizadas durante una sesión de estudio instrumental. Esta relación es extensiva a los diferentes instrumentos como se hace evidente en las conclusiones del estudio de García Martínez (2010) quien postula que los alumnos más avanzados son a su vez los que muestran mayor verbalización, mayor regulación metacognitiva y más alta conciencia del proceso de aprendizaje.

Una limitación de esta investigación fue no llegar a evaluar el impacto que tiene la utilización de estrategias metacognitivas de estudio en la performance instrumental de un clarinetista en formación. La tesis se centró en la identificación de las mismas más que en el análisis de una producción musical fruto del proceso de aprendizaje metacognitivo. Se recomienda para futuras investigaciones retomar este aspecto realizando un análisis que contemple la relación entre el estudio eficaz a partir de la utilización de las estrategias mencionadas y la ejecución del clarinete en una situación de examen y/o presentación en público, incluyendo el factor emocional como variable para estimar el grado en que un estudio eficaz incide en la performance instrumental. 


\section{Bibliografía}

Ausubel, D. (2003). Adquisición y retención del conocimiento. Una perspectiva cognitiva. Barcelona, España: Ed. Paidós

Bontempo, C. (2009). Le strategie didattiche metacognitive. Rivista digitale della didattica, Recuperado de http://www.rivistadidattica.com/pedagogia/pedagogia_86.htm

Burón, J. Ed. (1996). Enseñar a aprender: Introducción a la Metacognición. Bilbao, España: Ediciones Mensajero

Crespo, N. (2000). La Metacognición: Las diferentes vertientes de una Teoría. Revista electrónica Signo. Recuperado de http://www.scielo.cl/scielo.php?script=sci_arttext\&pid=S0718-09342000004800008

Eco, U. (1997). Cómo se hace una tesis: técnicas y procedimiento de estudio, investigación y escritura. Barcelona, España: Gedisa

Ericsson, K., \& Simon, H. (1993). Protocol Analysis: Verbal Reports as Data (2nd ed.). Boston, Estados Unidos: MIT Press.

Flavell, J. (1983). El desarrollo cognitivo. Madrid, España: Editorail Visor

Flavell, J. (1979). Metacognition and cognitive monitoring. A new Area of Cognitive Developmental Inquiry. Recuperado de http://psycnet.apa.org/index.cfm?fa=buy.optionToBuy\&id=1980-09388-001

García Martínez, R. (2010): Evaluación de las estrategias metacognitivas en el aprendizaje de contenidos musicales y su relación con el rendimiento académico musical (Tesis de Doctorado). Recuperado de http://www.tdx.cat/bitstream/handle/10803/62136/garcia.pdf 
Gilad, Y. (26 de enero de 2016). 7 tips for clarinetists from Yehuda Gilad [Mensaje de Blog]. Recuperado de https://www.playwithapro.com/blog/7-tips-for-clarinetists-fromyehuda-gilard-91

Heit, I. A. (2011). Estrategias metacognitivas de compresión lectora y eficacia en la Asignatura Lengua y Literatura (Tesis de Licenciatura). Universidad Católica Argentina Facultad Teresa de Ávila Departamento de Humanidades, Paraná, Argentina.

Lacon, N. \& Ortega, S. (2008). Cognición, metacognición y escritura. Revista Signos. Recuperado de http://www.scielo.cl/scielo.php?script=sci_arttext\&pid=S071809342008000200009

Malbrán, M. y Marincoff, G. (2011). Estudio de Procesos Metacognitivos. Universidad Nacional de La Plata. 10 de junio de 2011

Manes, F. y Niro, M. (2014). Usar el cerebro. Usar nuestra mente para vivir mejor. . Buenos Aires, Argentina: Editorial Planeta (p 105)

Mateos, M. (2001). Metacognición y educación. En I. A. Heit. Estrategias metacognitivas de compresión lectora y eficacia en la Asignatura Lengua y Literatura. (Tesis de Licenciatura) (pp.16). Universidad Católica Argentina Facultad Teresa de Ávila Departamento de Humanidades, Paraná, Argentina.

Perez, C. (2008): Teoría Triárquica de Sternberg (tesis de maestría). Universidad de Concepción Facultad de Educación, Concepción, Chile.

Requena, M. (2003). El análisis de protocolo como técnica para la comprensión de los procesos de razonamiento. Recuperado de http://www.redalyc.org/pdf/761/76111331007.pdf 
Román Peréz, M. y Díez López, E. (2009). La inteligencia escolar aplicaciones al aula. Una nueva teoría para una nueva sociedad. Santiago de Chile, Chile: Editorial Conocimiento

Sternberg, R. (1985). The Triarchic mind. Nueva York, Estados Unidos: Penguin Books

Valitutti, G. (2008). La scuola del successo e la meta cognizione. Recuperado el 15 julio, 2013 de http://educa.univpm.it/strategie/scusumet.html 


\section{Anexos}

\section{Cuestionario de autoinforme}

Encuesta: "Conciencia metacognitiva al estudiar un instrumento musical. Orientada a instrumentistas en formación. Especialidad: Clarinete

Presentación: Estudiantes de la Facultad de Bellas Artes de la Universidad de La Plata están

llevando a cabo una investigación. Tu tarea en este cuestionario será de gran utilidad para

dicho estudio. Toda la información proporcionada será tratada con confidencialidad.

Agradecemos tu valiosa colaboración

EDAD:

NIVEL ACADÉMICO:

Consigna: Para cada enunciado marca $(\mathrm{X})$ según se aplique o no a tu caso.

Situación sugerida: Te encuentras en el momento de abordar el estudio con el instrumento (clarinete) de una nueva obra musical. ¿Cuáles de los siguientes enunciados se ajustan al proceso de tu práctica?

\begin{tabular}{|c|c|c|c|c|}
\hline $\mathrm{N}^{\circ}$ & Items & SI & A VECES & NO \\
\hline 1 & Trato de usar estrategias que en el pasado han sido exitosas & & & \\
\hline 2 & $\begin{array}{l}\text { Me propongo metas específicas antes de comenzar la práctica } \\
\text { instrumental }\end{array}$ & & & \\
\hline 3 & Sé si voy logrando mi meta & & & \\
\hline 4 & Practico diariamente la obra que estoy preparando & & & \\
\hline 5 & Tengo conciencia de mi logros paulatinos & & & \\
\hline 6 & Las estrategias que utilizo tienen un propósito específico & & & \\
\hline 7 & $\begin{array}{l}\text { Sé lo que el profesor quiere que aprenda con la obra o estudio que estoy } \\
\text { preparando }\end{array}$ & & & \\
\hline 8 & $\begin{array}{l}\text { Pido ayuda cuando no entiendo cómo debo ejecutar algún } \\
\text { pasaje con el clarinete }\end{array}$ & & & \\
\hline 9 & Cuando estudio tengo conciencia de las estrategias que empleo & & & \\
\hline
\end{tabular}




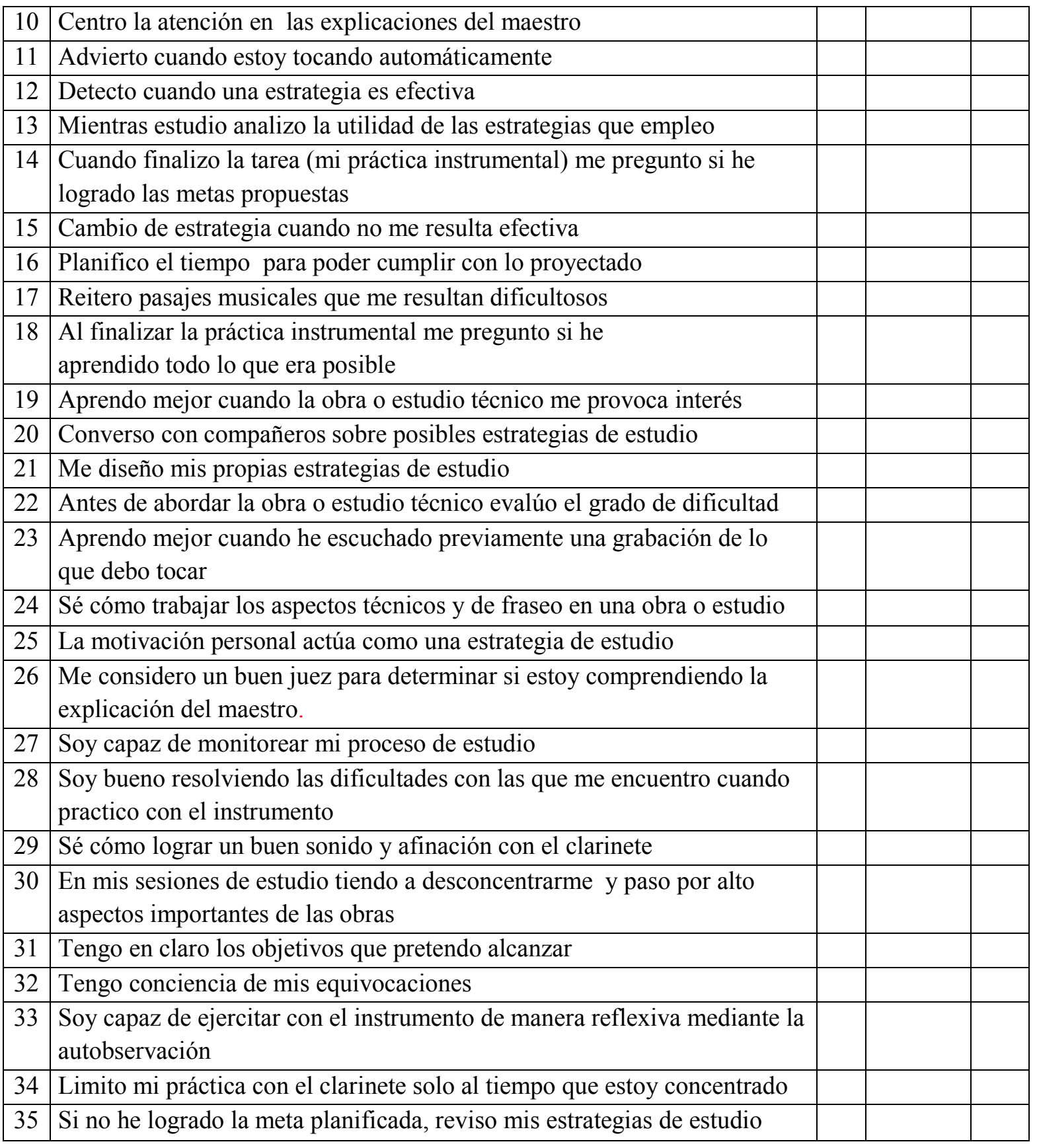


II. Correos electrónicos. Comunicación directa con docentes de clarinete, pedagogos e investigadores.

----Messaggio originale----

Da: paulatemp@hotmail.com

Data: 14-set-2014 1.44

A: "gvalitutti@virgilio.it"<gvalitutti@virgilio.it>

Ogg: La scuola del successo e la metacognizione.

Stimato professor Valitutti:

ho avuto l'opportunità di leggere un suo testo: "La Scuola del Successo e la metacognizione", (Università di Urbino "Carlo Bo"). E 'molto interessante e l' ho incorporato qualque considerazione per un mio lavoro scolastico. Vorrei sapere la data di quando ha scritto questo testo. Le mando i miei cordiale salutti.

Paula Caputo

Da: gvalitutti@virgilio.it (gvalitutti@virgilio.it)

A: paulatemp@hotmail.com

Gentile Collega, ho scritto quel file 5-6 anni fa. Potrà trovarne altri, ugualmente interessanti, sul sito del prof. Cardellini "Educando". Consulti pure il sito dell'INDIRE sull'educazione scientifica risorsedocentipon.indire.it oppure www.leparoledellascienza.it .Buon lavoro. Giuseppe Valitutti 
De: paula caputo [mailto:paulatemp@hotmail.com]

Enviado el: jueves, 05 de junio de 2014 9:46

Para: contact@rossiclarinet.com; rossiclarinet@terra.cl

Asunto: Consulta- dos preguntas

Estimado Luis Rossi, mi nombre es Paula Caputo. Hace unos 3 años tomé unas clases

particulares con Carlos Céspedes, quien me hizo conocer su método técnico. En este momento estoy trabajando para terminar mi tesis de maestría en Psicología de la Música que he titulado "Estrategias metacognitivas en el aprendizaje del clarinete".

Me gustaría incluir su opinión sobre el aprendizaje y la enseñanza del instrumento a través de dos preguntas simples que transcribo más abajo. Si sus obligaciones se lo permiten, le agradecería enormemente su valioso aporte.

1- ¿Cómo guía un docente a sus alumnos en el camino del propio monitoreo al momento de estudiar un instrumento, en este caso, el clarinete?

2- ¿Qué estrategias utiliza cuando enseña, para ayudar a sus alumnos a resolver pasajes que les son dificultosos en una obra musical y/o ejercicio técnico? ¿Tienden a la autorregulación? Mil gracias.

Paula Caputo 
From: contact@,rossiclarinet.com

To: paulatemp@hotmail.com

Subject: RE: Consulta- dos preguntas

Date: Thu, 5 Jun 2014 10:36:47 -0400

Estimada Paula:

Le contestaré brevemente y si es necesario ahondar me vuelve a preguntar.

1) El aprendizaje está basado en el estudio de las escalas, en el cual el profesor educa al alumno en el camino de lograr una perfección no sólo en la regularidad, sino también en el sonido y la delicadeza con que deben practicarse. Esto va desarrollando una sensibilidad y ayuda a agudizar la percepción del alumno con respecto a sus resultados. Esta misma exigencia sigue en los estudios técnicos y finalmente en las obras musicales. Las correcciones del profesor serán su guía, para recordar que es lo que se debe cuidar, oír y mejorar.

2) Fundamentalmente el concepto de la relajación. La cual no se logra sin antes desarrollar la técnica del apoyo diafragmático.

Ambas cosas van encadenadas. Si existe esta base, luego se puede trabajar un pasaje a diferentes velocidades, para lograr la eficiencia y coordinación de los dedos, sin que haya tensiones musculares que impidan llegar a la velocidad buscada.

Cordialmente,

Luis Rossi

De: paula caputo [mailto:paulatemp@hotmail.com]

Enviado el: domingo, 15 de junio de 2014 8:19 
Para: Luis Rossi

Asunto: RE: Consulta- dos preguntas

Estimado Maestro

Le agradezco enormemente su aporte. Siempre tan clarificador. Ahora me gustaría profundizar en el concepto de la autorregulación al momento de estudiar. ¿En qué aspectos del estudiante se basa para evaluar su manera de estudiar y su propio monitoreo?, tan importante es esta disciplina en la que muchas veces son más las horas que pasamos solos estudiando que las que podemos estar acompañados por el docente.

Muchas gracias nuevamente. Saludos cordiales

Paula Caputo

RE: Consulta- dos preguntas

Luis Rossi

$15 / 06 / 2014$

Para: 'paula caputo'

Estimada Paula:

En mi opinión, el estudio personal debe estar basado en desarrollar el concepto de la relajación muscular. Esto debe llegar a ser una vivencia física, el sentir que -mientras se sopla y se toca- se logra una armonía muscular, física, libre de tensiones. Un estado físico similar al que se estudia en las clases de Yoga. Si el alumno no desarrolla esta postura física, tendrá muchos problemas que arrastrará a lo largo de su carrera, en algunos casos con tendinitis y otros más graves como la fatal distonía. He visto varios casos de este tipo. Todo 
este trabajo introspectivo se debe hacer durante la rutina diaria de las escalas, la que es similar al entrenamiento diario de un deportista.

Luego, durante la práctica de los Estudios y de las Obras, ayuda mucho el grabar y luego escuchar lo que realmente uno hace. Porque mientras uno está involucrado en el proceso de tocar, generalmente no conserva toda la capacidad de monitorear el resultado.

Cordialmente,

Luis Rossi

From: paula caputo <paulatemp@hotmail.com>

Date: Saturday, January 16, 2016 at 12:08 PM

To: Robert Sternberg <rjs487@cornell.edu $>$

Subject: RE: Consulta teoría triárquica de la inteligencia - Tesis

Estimado Profesor Robert Stenberg:

Mi nombre es Paula Caputo y hace un tiempo me puse en contacto con usted. Estoy finalizando una Maestría en Psicología de la Música, en la Universidad de La Plata, Buenos Aires, Argentina. Incorporé en mi tesis su teoría triárquica de la inteligencia y me gustaría hacerle algunas consultas específicas en torno a la ejecución instrumental.

Según sus estudios la teoría se denomina triárquica porque postula tres tipos de inteligencias:

La inteligencia analítica, la inteligencia creativa y la inteligencia práctica. ¿Se le ocurre alguna manera de ejemplificar dichos aspectos durante una práctica instrumental?

Agradecería su valioso aporte en mi investigación.

Saludos cordiales

Paula Caputo 
Date: Saturday, January 16, 2016 at 12:08 PM

To: Robert Sternberg < rjs487@,cornell.edu $>$

Subject: RE: Consulta teoría triárquica de la inteligencia - Tesis

Para: paula caputo

Si.

Creativa es en la musicalidad. La diferencia en su instrumento entre Jacqueline Du Pre y todos los otros en Cello, Concierto de Elgar, su creatividad en revelar la música. Analítica es en la exactitud de la comprensión de la música, lo que intento el compositor. Práctica es en la conexión con la audiencia. Algunos músicos la tienen, otros no. Como la audiencia responde.

Lo mejor, Bob

Robert J. Sternberg

Professor of Human Development. Department of Human Development. Cornell University. B44 MVR. 116 Reservoir Ave.

Ithaca, NY 14853. www.robertjsternberg.com 